\title{
Surface-enhanced Raman spectroscopic studies of the orientation of organonitriles on metal colloids
}

\author{
Ramaa Nagapattinam Ramakrishnan \\ West Virginia University
}

Follow this and additional works at: https://researchrepository.wvu.edu/etd

\section{Recommended Citation}

Ramakrishnan, Ramaa Nagapattinam, "Surface-enhanced Raman spectroscopic studies of the orientation of organonitriles on metal colloids" (2000). Graduate Theses, Dissertations, and Problem Reports. 1145. https://researchrepository.wvu.edu/etd/1145

This Thesis is protected by copyright and/or related rights. It has been brought to you by the The Research Repository @ WVU with permission from the rights-holder(s). You are free to use this Thesis in any way that is permitted by the copyright and related rights legislation that applies to your use. For other uses you must obtain permission from the rights-holder(s) directly, unless additional rights are indicated by a Creative Commons license in the record and/ or on the work itself. This Thesis has been accepted for inclusion in WVU Graduate Theses, Dissertations, and Problem Reports collection by an authorized administrator of The Research Repository @ WVU. For more information, please contact researchrepository@mail.wvu.edu. 


\title{
Surface enhanced Raman Spectroscopic studies of the orientation of organonitriles on metal colloids
}

\author{
Ramaa N Ramakrishnan \\ Thesis submitted to the College of Arts and Sciences \\ at West Virginia University \\ In partial Fulfillment of the Requirements \\ For the Degree of \\ Master of Science \\ In \\ Chemistry \\ Paul W. Jagodzinski, Ph.D., Chair \\ Harry O. Finklea, Ph.D. \\ Charles Jaffe, Ph.D. \\ Department of Chemistry
}

West Virginia University, Morgantown

2000

Keywords: Gold colloid, Copper colloid, SERS, orientation 


\begin{abstract}
Surface enhanced Raman spectroscopic studies of the orientation of organonitriles on metal colloids
\end{abstract}

\title{
Ramaa N Ramakrishnan
}

The orientation of adsorbates on metal colloids was studied by Surface enhanced Raman spectroscopy. We studied the orientation of cyanopyridines, aminomethylpyridines and 4-biphenylcarbonitrile on gold and copper colloids as a function of concentration of the adsorbates. It was found that the orientation of the adsorbate did not change as a function of concentration when adsorbed on gold colloids and was end-on for all concentrations. The orientation of 4-biphenylcarbonitrile was flaton on gold colloid. The orientation of the adsorbate changed with change in concentration when adsorbed on copper colloids. The orientation was flat-on for higher concentrations and end-on for lower concentrations of 4- and 3-aminomethylpyridines. The orientation was end-on for higher concentrations and flat-on for lower concentrations for 2aminomethylpyridines when adsorbed on copper colloid. We modeled the surfaceadsorbate system using SpartanPro software and calculated the frequencies. The frequencies obtained for these systems were in close agreement with the experimental results. 


\section{ACKNOWLEDGEMENTS}

I owe this thesis to my professors, family members and friends as they helped me through a difficult stage of my life. The person whom I should thank foremost is my research advisor, Dr. Paul W. Jagodzinski whose patience and encouragement has helped me to work through this thesis. He has thought me that there is no limit for help and cooperation a person can extend towards others.

My sincere acknowledgement is due for my laboratory coworkers Candace Coyle, Chen Zuo, Yigang Jin and Michael Jacobs. I thank Dr. Candace Coyle for helping me get started with my work. My thanks are due for Chen Zuo who has extended his help 'out of his way' during my days at this laboratory. I also thank Michael Jacobs and Yigang Jin for their help, cooperation and for being good friends during my stay at the university. My sincere thanks are also due for Dr. Robert Smart who arranged for a suitable schedule for my teaching assistantship during my stay in the last semester, Barbara Foster and Matt Lalka for their cooperation in carrying out my teaching assistant work.

I also thank all the professors who offered me the courses and helped in improving my knowledge in the subject and also my friends in the department whose friendliness has made me enjoy my stay at this university.

Finally I acknowledge the support provided by my parents, sisters and husband to make me work on this thesis. 


\section{TABLE OF CONTENTS}

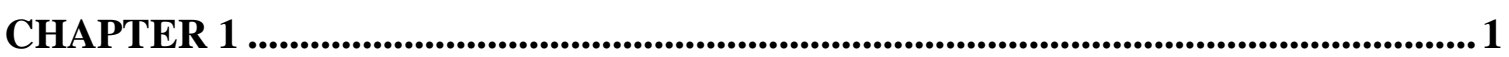

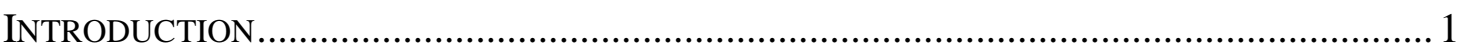

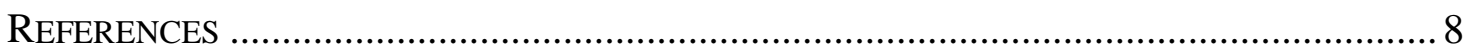

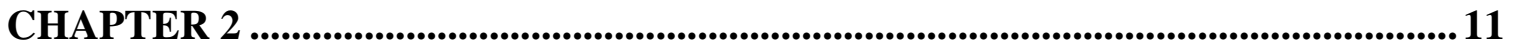

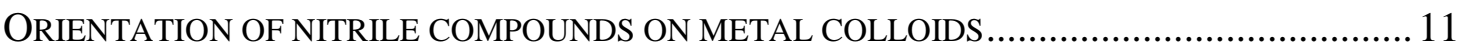

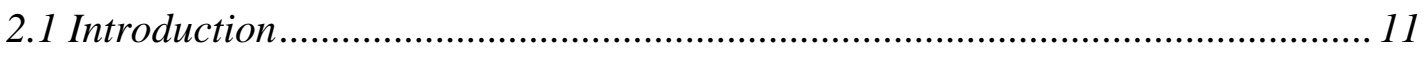

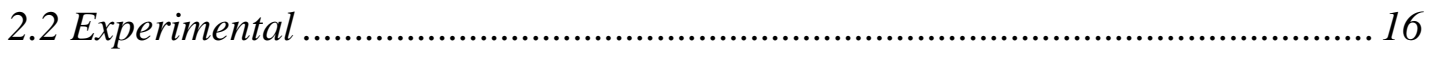

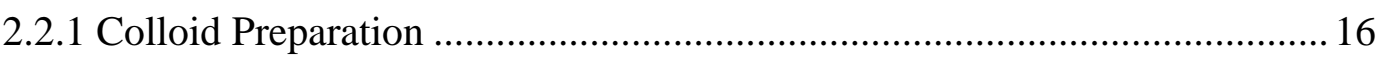

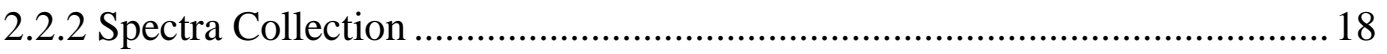

2.3 Results and Discussion............................................................................ 19

2.3 .1 Study of orientation of cyanopyridines on gold colloid ......................... 19

2.3 .2 Study of orientation of 4-biphenylcarbonitrile on gold colloid: .................38

2.3.3 Study of orientation of aminomethylpyridines on copper colloid: ............46

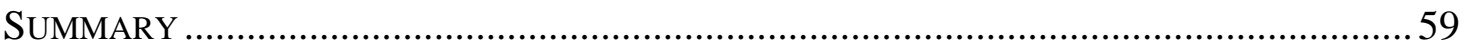

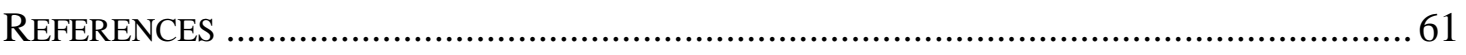

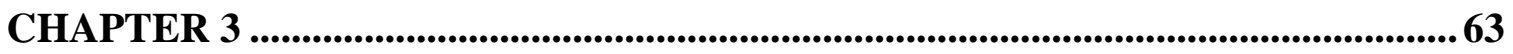

MOLECULAR MODELING STUDIES OF SURFACE-ADSORBATE

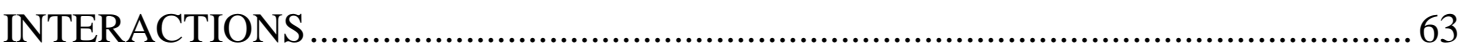

3.1 Introduction .................................................................................. 63

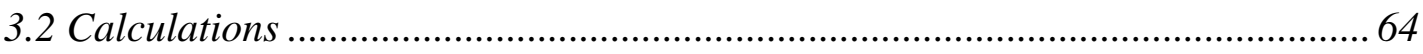

3.3 Results And Discussion .................................................................. 65 
B.3.1 4-cyanopyridines on gold colloids: ....................................................65

8.3.2 3-cyanopyridines on gold colloids: ...................................................... 66

8.3.3 2-cyanopyridines on gold colloids: ..................................................... 70

B.3.4 4-biphenylcarbonitriles on gold colloids:............................................ 72

3.3.5 Aminomethylpyridine on copper colloids:............................................. 72

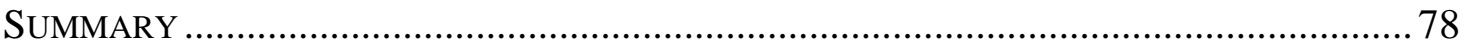

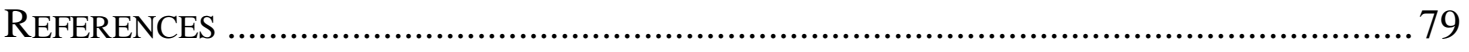

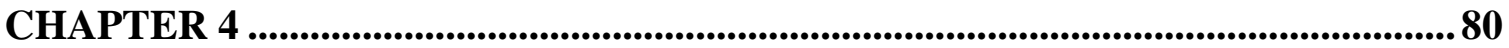

SCOPE FOR FUTURE INVESTIGATION .................................................................. 80

ABSTRACT ....................................................................................................................... 2

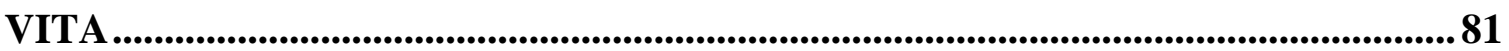




\section{LIST OF FIGURES}

FIGURE 2.1 ORIENTATION OF 4- CYANOPYRIDINE ON METAL SURFACE (A) END-ON

ORIENTATION THROUGH AROMATIC NITROGEN (B) FLAT-ON ORIENTATION (C) END-ON

ORIENTATION THROUGH NITRILE NITROGEN. A 3-DIMENSIONAL DISPLAY OF THE

MOLECULE CAN SHOW THE FLAT-ON ORIENTATION OF THE MOLECULE PARALLEL TO

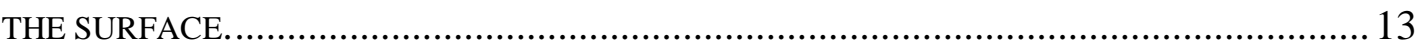

FIGURE 2.2 RAMAN SPECTRA OF 4-CYANOPYRIDINE AND SERS OF 4-CYANOPYRIDINE OF

VARIOUS CONCENTRATIONS ADSORBED ON GOLD COLLOIDS (A) PARENT 4-

CYANOPYRIDINE, (B) AU/2X10-2 M 4-CYANOPYRIDINE, (C) Au/1X10-2 M 4-

CYANOPYRIDINE, (D) AU/1X10-3 M 4-CYANOPYRIDINE, (E) AU/1X10 $0^{-4} \mathrm{M}$ 4-

CYANOPYRIDINE, (F) AU/1X10 ${ }^{-6} \mathrm{M}$ 4-CYANOPYRIDINE......................................21

FIGURE 2.3 SUGGESTED GRADUAL CHANGE IN THE ORIENTATION OF 4-CYANOPYRIDINES

ON GOLD COLLOID WITH CHANGE IN CONCENTRATION OF 4-CYANOPYRIDINE ............25

FIGURE 2.4(I) RAMAN SPECTRA OF 3-CYANOPYRIDINE AND SERS OF 3-CYANOPYRIDINE OF

VARIOUS CONCENTRATIONS ADSORBED ON GOLD COLLOID (A) PARENT 3-

CYANOPYRIDINE (B) Au/ 2X10-2 M 3-CYANOPYRIDINE (C) Au/1X10-2 M 3-

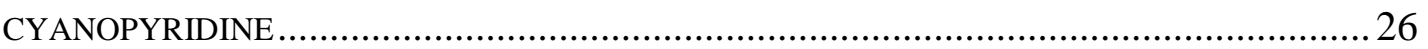

FIGURE 2.4 (II) SERS OF 3-CYANOPYRIDINES OF VARIOUS CONCENTRATIONS ADSORBED ON

GOLD COLLOID (D) AU/1X10-3 M 3-CYANOPYRIDINE (E) AU/1X10 ${ }^{-4} \mathrm{M} 3-$

CYANOPYRIDINE (F) AU/1X10 ${ }^{-6} \mathrm{M}$ 3-CYANOPYRIDINE ........................................ 27

FIGURE 2.5 SUGGESTED GRADUAL CHANGE IN ORIENTATION OF 3-CYANOPYRIDINE ON

GOLD COLLOID WITH CHANGE IN CONCENTRATION OF 3-CYANOPYRIDINE .................. 32 
FIGURE 2.6(I) RAMAN SPECTRUM OF 2-CYANOPYRIDINE AND SERS OF 2-CYANOPYRIDINE ADSORBED ON GOLD COLLOIDS.(A) PARENT 2-CYANOPYRIDINE (B) AU/2X10-2 M 2-

CYANOPYRIDINE (C) AU/1X10 ${ }^{-2} \mathrm{M}$ 2-CYANOPYRIDINE....................................... 33

FIGURE 2.6 (II) SERS OF AU/1X10 $10^{-5} \mathrm{M}$ 2-CYANOPYRIDINE ADSORBED ON GOLD COLLOID. 34 FIGURE2.6(III) SERS OF 2-CYANOPYRIDINE ADSORBED ON GOLD COLLOID.(E) AU/1X10-4 M

2-CYANOPYRIDINE (F) AU/1X10-6 M 2-CYANOPYRIDINE..................................... 35

FIGURE 2.7 SUGGESTED GRADUAL CHANGE IN THE ORIENTATION OF 2-CYANOPYRIDINE ON

GOLD COLLOIDS WITH CHANGE IN THE CONCENTRATION OF 2-CYANOPYRIDINE..........39

FIGURE 2.8 RAMAN SPECTRUM OF 4-BIPHENYLCARBONITRILE AND SERS OF 4-

BIPHENYLCARBONITRILE OF VARIOUS CONCENTRATIONS ADSORBED ON GOLD

COLLOID. (A)PARENT 4-BIPHENYLCARBONITRILE IN CCL 4 (B) AU/1X10 ${ }^{-4} \mathrm{M} 4-$

BIPHENYLCARBONITRILE (C) AU/1X10 $0^{-5} \mathrm{M}$ 4-BIPHENYLCARBONITRILE (D) AU/1X10-

PM 4-BIPHENYLCARBONITRILE ..................................................................... 40

FIGURE 2.9 SUGGESTED GRADUAL CHANGE IN THE ORIENTATION OF 4-

BIPHENYLCARBONITRILE ON GOLD COLLOID WITH CHANGE IN CONCENTRATION OF 4-

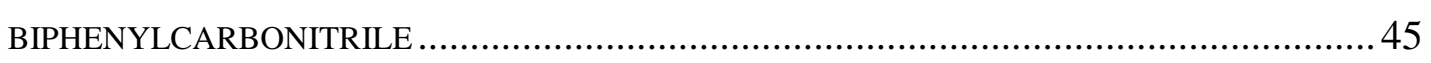

FIGURE 2.10 RAMAN SPECTRUM OF 4-AMINOMETHYLPYRIDINE AND SERS OF 4-

AMINOMETHYLPYRIDINES OF VARIOUS CONCENTRATIONS ADSORBED ON COPPER

COLLOIDS.(A)PARENT 4-AMINOMETHYLPYRIDINE (B)CU/1.7X10-2 M 4-

AMINOMETHYLPYRIDINE (C)CU/8.7X10-3 M 4-AMINOMETHYLPYRIDINE(D)CU/8.7X10-

[M 4-AMINOMETHYLPYRIDINE (E) CU/8.7X10-5 M 4-AMINOMETHYLPYRIDINE

(F)CU/8.7 X10 ${ }^{-6} \mathrm{M}$ 4-AMINOMETHYLPYRIDINE (G)CU/8.7 X10 ${ }^{-7} \mathrm{M} 4-$

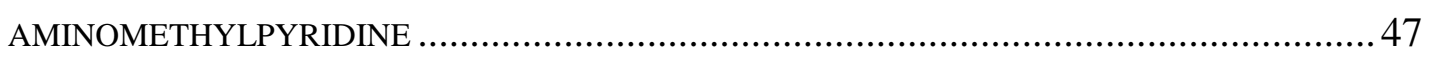


FIGURE 2.11 RAMAN SPECTRUM OF 3-AMINOMETHYLPYRIDINE AND SERS OF 3-

AMINOMETHYLPYRIDINES OF VARIOUS CONCENTRATION ADSORBED ON COPPER

COLLOIDS. (A) PARENT 3-AMINOMETHYLPYRIDINE (B) CU/1.7X10-2 M 3-

AMINOMETHYLPYRIDINE (C) CU/8.7X10 $10^{-5} \mathrm{M}$ 3-AMINOMETHYLPYRIDINE (D)

CU/8.7X10-4 M 3-AMINOMETHYLPYRIDINE (E) CU/8.7X10 ${ }^{-5} \mathrm{M} 3-$

AMINOMETHYLPYRIDINE (F) CU/8.7X10-6 M 3-AMINOMETHYLPYRIDINE (G)

CU/8.7X10 


\section{LIST OF TABLES}

TABLE 2.1 FINAL CONCENTRATIONS IN SOLUTION OF THE SPECIES USED FOR THE PREPARATION OF GOLD COLLOID AND COPPER COLLOID ......................................... 17

TABLE 2.2 RAMAN FREQUENCIES OF NEAT 4 CYANOPYRIDINES(4-CP) AND SERS FREQUENCIES OF VARIOUS CONCENTRATIONS OF 4-CYANOPYRIDINE ADSORBED ON GOLD COLLOIDS. CONCENTRATION OF 4 CYANOPYRIDINES ADSORBED ON THE

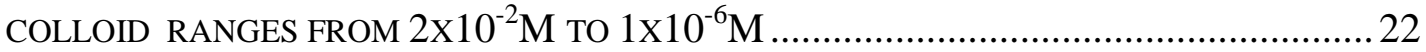

TABLE 2.3 RAMAN FREQUENCIES OF NEAT 3-CYANOPYRIDINES(3-CP) AND SERS FREQUENCIES OF VARIOUS CONCENTRATIONS OF 3-CYANOPYRIDINE ADSORBED ON GOLD COLLOIDS. CONCENTRATION OF 3-CYANOPYRIDINES ADSORBED ON THE

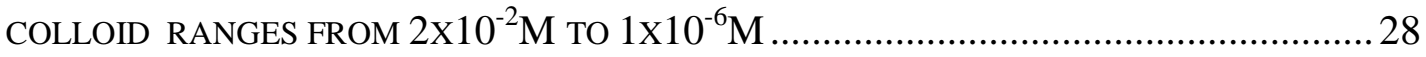

TABLE 2.4 RAMAN FREQUENCIES OF NEAT 2-CYANOPYRIDINE(2-CP) AND SERS FREQUENCIES OF VARIOUS CONCENTRATIONS OF 2-CYANOPYRIDINE ADSORBED ON GOLD COLLOIDS. CONCENTRATION OF 2-CYANOPYRIDINES ADSORBED ON THE

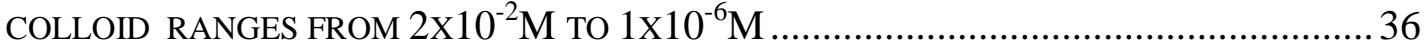

TABLE 2.5 RAMAN FREQUENCIES OF 4-BIPHENYLCARBONITRILE (4-BPN) AND SERS FREQUENCIES OF VARIOUS CONCENTRATION OF 4-BPN ADSORBED ON GOLD COLLOID. THE CONCENTRATION OF 4-BPN IN SOLUTION RANGES FROM $1 \times 10^{-4} \mathrm{M}$ TO $1 \times 10^{-6} \mathrm{M} .41$

TABLE 2.6 RAMAN FREQUENCIES OF NEAT 4-AMINOMETHYLPYRIDINE (4-AMP) AND SERS FREQUENCIES OF VARIOUS CONCENTRATIONS OF 4-AMINOMETHYLPYRIDINE ADSORBED ON COPPER COLLOIDS. THE CONCENTRATION OF 4-AMINOMETHYLPYRIDINE

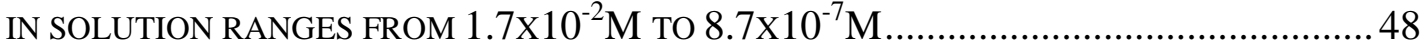


TABLE 2.7 RAMAN FREQUENCIES OF NEAT 3-AMINOMETHYLPYRIDINE (3-AMP) AND SERS FREQUENCIES OF VARIOUS CONCENTRATIONS OF 3-AMINOMETHYLPYRIDINE ADSORBED ON COPPER COLLOIDS. THE CONCENTRATION OF 3-AMP IN SOLUTION RANGES FROM 1.7X10-2 M TO 8.7X10

TABLE 2.8 RAMAN FREQUENCIES OF NEAT 2-AMINOMETHYLPYRIDINE (2-AMP) AND SERS FREQUENCIES OF VARIOUS CONCENTRATIONS OF 2-AMINOMETHYLPYRIDINE ADSORBED ON COPPER COLLOIDS. THE CONCENTRATION OF 2-AMINOMETHYLPYRIDINE

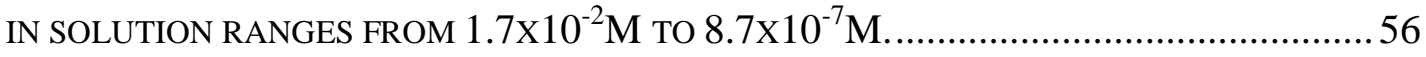

TABLE 3.1 COMPARISON OF FREQUENCIES OF SOME OF THE IMPORTANT BAND ASSIGNMENTS OBTAINED FROM THE MODEL SYSTEM AND EXPERIMENT FOR AU/4CP SYSTEMS(MM=MOLECULAR MECHANICS) ..................................................... 67

TABLE 3.2 COMPARISON OF FREQUENCIES OF SOME OF THE IMPORTANT BAND ASSIGNMENTS OBTAINED FROM MODEL SYSTEM AND EXPERIMENT FOR AU/3CP SYSTEM(MM=MOLECULAR MECHANICS) ..................................................... 69

TABLE 3.3 COMPARISON OF FREQUENCIES OF SOME OF THE IMPORTANT BAND ASSIGNMENTS OBTAINED FROM MODEL SYSTEM AND EXPERIMENT FOR AU/2CP

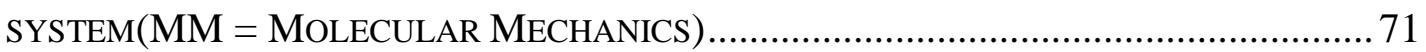

TABLE 3.4 COMPARISON OF FREQUENCIES OF SOME OF THE IMPORTANT BAND ASSIGNMENTS OBTAINED FROM MODEL SYSTEM AND EXPERIMENT FOR AU/4BPN SYSTEM (MM = MOLECULAR MECHANICS) .................................................... 73

TABLE 3.5 COMPARISON OF VALUES OF FREQUENCIES OF SOME OF THE IMPORTANT BAND ASSIGNMENTS OBTAINED FROM MODEL SYSTEM AND EXPERIMENT FOR CU/4AMP SYSTEM (MM = MOLECULAR MECHANICS) 
TABLE 3.6 COMPARISON OF FREQUENCIES OF SOME OF THE IMPORTANT BAND ASSIGNMENTS OBTAINED FROM MODEL SYSTEM AND EXPERIMENT FOR CU/3AMP

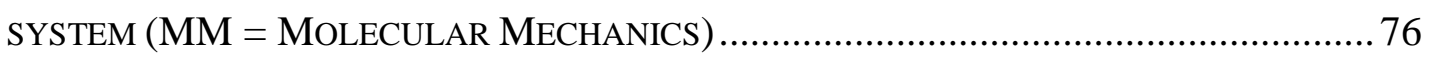

TABLE 3.7 COMPARISON OF FREQUENCIES OF SOME OF THE IMPORTANT BAND ASSIGNMENTS OBTAINED FROM MODEL SYSTEM AND EXPERIMENT FOR CU/2AMP

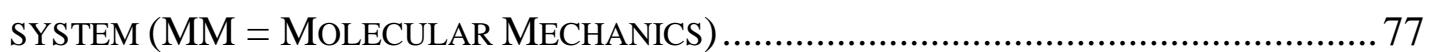




\section{CHAPTER 1}

\section{Introduction}

Surface enhanced Raman spectroscopy (SERS) refers to the observation that for certain molecules adsorbed on specially prepared metal surfaces a Raman spectrum is observed with higher intensity. The intensity of the Raman spectrum exceeds the intensity observed for those molecules when not adsorbed on a metal surface by a factor of $10^{5}$ $10^{6}$. The information obtained from SERS gives details about the nature of the surface and surface-molecule interactions. ${ }^{1,2}$

The SERS phenomenon was first observed by Fleischmann et.al in $1974 .^{3}$ They observed an enhancement of signal from the pyridine molecule in aqueous solution adsorbed onto a silver electrode which was roughened by means of successive oxidation-reduction cycles. The observation of this phenomenon was also reported by Van Duyne et.al in 1977 and Creighton et.al in 1977. ${ }^{4,5}$ Since then the effect has been reported for several molecules adsorbed on silver, gold, copper, lithium, sodium, potassium, indium, aluminum, platinum, and rhodium. ${ }^{1}$ To observe SERS, the system requires a roughened metal surface and a molecule that can be adsorbed on it.

SERS is efficient in transforming Raman spectroscopy into a highly sensitive technique capable of ultramicro analysis. The molecule specificity of the SERS technique has the potential to resolve a mixture into its individual active components. Due to the large surface enhancement and the small volumes required, SERS is a very useful analytical 
technique. The SERS surface enhances the Raman signal produced by the component(s) of the sample so that nanogram amounts of material can routinely be detected.

The discovery of SERS has stimulated enormous interest in Raman spectroscopy of surfaces and in the study of biological molecules adsorbed onto surfaces. ${ }^{6}$ Apart from this it has stimulated and resurrected activity in classical electrostatic and electromagnetic theory, in the problem of radiating multipoles near metal surfaces, in optics of small particles, in the generation of surface plasmons, in theoretical and experimental investigations of the optical properties of metallic gratings and molecules placed near them, in the study of the properties of aqueous metal sols and nonmetal colloids such as those of polymers, in enhanced photoemission by gratings and in light emission of metal particles excited by inelastic electron tunneling. ${ }^{7,8}$ It has also prompted interest in areas such as electrochemistry, charge transfer, and the chemical aspects of adsorption. The applications of SERS have been described in the review paper by Martin Moskovitis. ${ }^{9}$

\section{The nature of the effect:}

The nature of SERS can be explained by two separate mechanisms, namely, the Electromagnetic Mechanism (EM) and the Charge-Transfer Mechanism (CT). The Electromagnetic Mechanism explains SERS in terms of the metal surface and the ChargeTransfer Mechanism explains SERS in terms of the adsorbed molecule. ${ }^{10,11,12}$ Various models have been developed to explain SERS. Roughness of the surface is an essential factor for SERS to occur.

It has been observed that SERS is a collective effect appearing in surfaces composed of closely interacting structures. In the EM mechanism, a flat surface of a good conductor is 
considered and is defined as the surface plasmon. The surface plasmon consists of closely placed metal atoms which are coupled to each other. The coupling between the metal atoms produces an electromagnetic field at the surface of a plasmon and thus has an electromagnetic resonance. The surface is made rough on a nanometric scale by ruling it with a grating. It then contains very complex electromagnetic (EM) modes which can modify the spectroscopic properties of the adsorbed molecule in a radical manner by changing the field of the photons incident on the molecule. When a molecule is placed near it, the molecule acts as a dipole and creates an electromagnetic field. When the molecule near the metal surface is illuminated by both a direct and reflected field, an enhancement of the electromagnetic field occurs near the metal surface yielding up to a four-fold increase in intensity. Electromagnetic enhancement of a Raman signal depends on the total electric field at the molecular position. Large SERS signals are expected when both the frequency of the incident and Raman scattered beams approach the surface-plasmon resonance conditions. The typical EM models treat the adsorbed molecule as a simple dipole in accounting for the response of the metal surface to the adsorbed molecule. Hence the model cannot distinguish differences between adsorbed molecules.

CT theory is based on the affinity of the free molecule for the surface. The basic idea is that the resonance scattering is caused by a transition involving the surface and the adsorbed molecule (since for the free molecule no electronic transitions exists in the resonance scattering energy region). Enhancement of Raman signals occurs due to a change in the molecular polarizability of the adsorbate caused by physical or chemical interactions between the adsorbate molecule and the surface. This theory is more 
sensitive to the nature of the adsorbed molecule than the EM theory and provides details about the molecule-metal surface interaction. This theory does not explain the differences due to the orientation of the adsorbed molecule and the distance from the surface.

SERS is a good technique for studying surface chemical properties such as the geometry, orientation and changes in orientation of the adsorbate on the surface, the nature of the surface bonding site, the nature of the chemisorptive bond and surface chemical reactions.

\section{Preparation of SERS active substrates:}

SERS occurs when the metal surface has many coupled microscopic metal domains. Various SERS active systems are:

1. Electrode surfaces. ${ }^{3}$ The electrode surface is subjected to oxidation-reduction cycles as a roughening technique. A halide salt forms at the electrode surface during one part of the cycle or the other and causes a non-uniform distribution of metal on the electrode surface.

2. Metal island films. ${ }^{13}$ Island films consist of small metal particles resting on a glass or quartz substrate. The island films are formed when the metal is deposited as vapor on a warm substrate. The elevated temperature of the substrate increases metal atom mobility, causing nuclei to grow into islands.

3. Cold deposited films. ${ }^{14}$ Metal vapor is deposited as a rough film on a substrate. Since the substrate is cold the metal depositions do not migrate to form islands. 
4. Metal spheroid assemblies. ${ }^{15}$ This consists of an array of approximately ellipsoidal shaped particles deposited on a silicon surface.

5. Metal Colloids. ${ }^{16}$ A dissolved metal salt is reduced by means of an appropriate reducing agent in an aqueous or non-aqueous medium. Coagulation leads to metal colloidal particles.

A metal surface thickness ranging from $50 \AA$ to $200 \AA$ is produced by these methods. The preparation of electrode surfaces has been the most common SERS active system. However the preparation of some metal colloids as a SERS active substrate is very easy and we have used metal colloids as the SERS active substrate for our studies.

\section{SERS of Adsorbates}

Fleischmann et.al and Van Duyne et.al reported surface enhancement of pyridine molecules adsorbed on silver electrodes. ${ }^{17,18}$ They reported the variation in the intensities of bands around $1000 \mathrm{~cm}^{-1}$ with variation in electrode potential. A band was observed at $216 \mathrm{~cm}^{-1}$ and was assigned to the ring nitrogen-silver surface stretching mode. This suggests adsorption occurs through the nitrogen atom of the pyridine ring.

Van Duyne ${ }^{19}$ reported a striking decrease in the intensity of the $v(C \equiv N)$ band near 2240 $\mathrm{cm}^{-1}$ for the series of molecules 4-cyano, 3-cyano and 2-cyanopyridines adsorbed on a silver electrode. ${ }^{19}$ This decrease was not seen in the Raman spectra of the free cyanopyridines. Intensity differences were also seen in the case of adsorbed methylpyridines. ${ }^{19}$ These relative intensity differences were reported to be due to different molecular orientations with respect to the surface. The resonant response of the electrons of the metal surface was reported to be principally responsible for the greatly 
enhanced scattering in these systems. Surface enhancement occurred only when laser light of $647.1 \mathrm{~nm}$ was used..$^{20}$

A wide range of adsorbates have now been reported to give SERS spectra on silver surfaces, including several unsaturated and saturated nitrogen bases, ${ }^{21,22,23}$ cyanide ions, ${ }^{24,25}$ thiocyanate ions, ${ }^{26}$ tetra-alkyl ammonium ions, triphenylphosphine, triphenylarsine, ethanethiolate, benzoate, ${ }^{27}$ p-nitrosodimethylaniline,${ }^{28}$ methyl orange and crystal violet. $^{21}$

\section{Our study}

In our studies, we have used gold and copper colloids as the surface active substrates. Studies were performed with cyanopyridines, aminomethyl pyridines and a carbonitrile adsorbed on the surface of the colloids in order to investigate the geometry of the molecules on the surface and changes that occur as a function of concentration. We have also attempted studies of molecule-surface interactions by modeling the reactions using Spartan Pro software. ${ }^{29}$

Previously studies have been done in our laboratory where 4-, 3-, 2- cyanopyridines were adsorbed on gold and copper colloids. The adsorption of cyanopyridines on gold colloids and copper colloids was found to be through the lone pair of electrons of the nitrogen atom of the aromatic ring. ${ }^{30}$ The studies were performed for a single concentration of the adsorbate. Earlier studies have shown that a change in concentration of adsorbates (that is the number of molecules getting adsorbed on the surface of the colloids) was found to have an impact on the surface coverage and on the orientation of the adsorbates. ${ }^{31,32}$ The surface coverage is higher at higher concentrations and the optimum geometry which can give higher surface coverage was assumed to be end-on. The surface coverage is lesser at 
lower concentrations and the optimum orientation that can give lower surface coverage was assumed to be flat-on.

It is believed molecules change their orientation in order to relieve steric strain and to give higher surface coverage. A flat-on orientation is assumed to reduce steric strain compared to the end-on orientation. The end-on orientation can give higher surface coverage than the flat-on orientation. Hence sterically hindered molecules will tend to assume flat-on orientation. Also at higher concentrations in order to accommodate the higher number of molecules to get adsorbed on the surface of the colloids, the molecule can assume an end-on orientation that can accommodate for higher surface coverage.

Hence we started studying the changes in orientation of the adsorbates by changing their concentration to investigate their behavior on the surface of the metal colloids. We have also used a large molecule, 4-biphenylcarbonitrile, to study its orientation on the metal colloid. 


\section{References}

1. J. A. Creighton, Analytical Proceedings, 30, 28, 1993.

2. T. M. Cotton, J. Kim, G. Chumanov, Journal of Raman Spectroscopy, 22, 729, 1991.

3. M. Fleischmann, P. J. Hendra, A. J. McQuillan, Chemical Physics Letters, 26, 163, 1974.

4. D. L. Jeanmaire, R. P. Van Duyne, Journal of Electroanalytical Chemistry, 84, $1,1977$.

5. M. G. Albrecht, J. A. Creighton, Journal of American Chemical Society, 99, $5215,1977$.

6. X. Dou, Y. Yamaguchi, H. Yamamoto, S. Doi, and Yukihiro Ozaki, Journal of Raman Spectroscopy, 29, 739, 1998.

7. J. G. Endriz, Applied Physics Letters, 25, 261, 1974.

8. J. Lambe, S. L. MCCarthy, Physical Review Letters, 37, 923, 1976.

9. M. Moskovitis, Reviews of Modern Physics, 57, 783, 1985.

10. H. Metiu, R. P. Das, Annual Review of Physical Chemistry, 35, 507-536, 1984

11. A. G. Brolo, D. E. Irish, B. D. Smith, Journal of Molecular Structure, 405, 29, 1977. 
12. S. S. Jha, Surface Science, 158, 190, 1985.

13. R. W. Wood, Philos. Mag., 38, 98, 1919.

14. M. Moskovitis, Chemical Physics Letters, 98, 498, 1983.

15. P. F. Liao, J. G. Bergmann, D. S. Chemla, Chemical Physics Letters, 82, 355, 1981.

16. J. A. Creighton in Surface Enhanced Raman Scattering, edited by R. K. Chang and T. E. Furtak (Plenum, New York), p. 315, 1982.

17. M. Fleischmann, P. J. Hendra, A. J. McQuillan, Chemical Physics Letters, 26, 163, 1974.

18. R. P. Van Duyne in Chemical and BioChemical Applications of Lasers, Vol. 4 edited by C. B. Moore (Academic Press, New York), p.101, 1978.

19. C. S. Allen, R. P. Van Duyne, Chemical Physics Letters, 63, 455, 1979.

20. U. Wenning, B. Pettinger, H. Wetzel, Chemical Physics Letters, 70, 49, 1980.

21. D. L. Jeanmaire, R. P. Van Duyne, Journal of Electroanalytical Chemistry, 84, 1, 1977.

22. R. Dornhaus, M. B. Long, R. E. Brenner, R. K. Chang, Surface Science, 93, $240,1980$.

23. G. R. Erdheim, R. L. Birke, J. R. Lambardi, Chemical Physics Letters, 69, 495, 1980. 
24. T. E. Furtak, Solid State Communications, 28, 903, 1978.

25. J. Billmann, G. Kovacs, A. Otto, Surface Science, 92, 153, 1980.

26. R. P. Cooney, E. S. Reid, M. Fleischmann, P. J. Hendra, Journal of Chemical Society, Faraday Transactions, 73, 1691, 1977; H. S. Gold, R. P. Buck, Journal of Raman Spectroscopy, 8, 323, 1979.

27. V. V. Marinyuk, R. M. Lazorenko-Manevich, Ya. M. Kolotrykin, Dokl. Akad. Nauk SSSR 242, 1382, 1978.

28. G. Hagen, B. Simic Glavaski, E. Yeager, Journal of Electroanalytical Chemistry, 88, 269, 1978.

29. PC Spartan Pro 1.0 Copyright $@ 1996-1999$, Wavefunction, Inc.

30. C. M. Coyle, G. Chumanov, P. W. Jagodzinski, Journal of Raman Spectroscopy, 29, 757, 1998.

31. J. E. Demuth, K. Christmann, P. N. Sanda, Chemical Physics Letters, 76, 201, 1980.

32. M. P. Soriaga, J. H. White, A. T. Hubbard, Journal of Physical Chemistry, 87, 3048, 1983. 


\section{CHAPTER 2}

\section{Orientation of nitrile compounds on metal colloids}

\subsection{Introduction}

SERS is a good technique for studying orientation and changes in orientation of adsorbates on surfaces. The comparisons of frequencies and intensities of the bands of the adsorbates on the metal surface with the frequencies and intensities of the bands of the free adsorbates helps to determine the orientation of the adsorbates with respect to the metal surface.

It has been shown that vibrations of the adsorbates that are parallel to the metal surface show small enhancement and vibrations of the adsorbates that are perpendicular to the metal surface show a large enhancement. ${ }^{1}$ SERS is strongly observed in systems that can couple plasmon-like electromagnetic resonance to electromagnetic plane waves of the small metal surfaces. ${ }^{2}$ The surface absorbs the photon and 'stores' the electromagnetic energy into the surface plasmon; this is delocalized in the direction parallel to the surface but localized in the perpendicular direction. Hence it is possible to conclude that the vibrations parallel to the surface are less enhanced and vibrations perpendicular to the surface are greatly enhanced. The enhancement is also greater when the vibrational normal mode is symmetric. ${ }^{3,4}$ The SERS substrates localize the photon, by plasmon excitation, in all directions and the resulting concentration of electromagnetic energy is larger than when not adsorbed on the surface producing the enhancement. Strong enhancement will be observed when the particle size is smaller than wavelength of the 
incident light, the frequency of excitation or scatter is near the surface-plasmon resonance condition and the molecule is not too far removed from the surface.,

Previous studies have showed that cyanopyridines adsorbed onto silver electrodes exhibit a surface enhancement that is dependent on the position of the nitrile moiety on the aromatic ring. ${ }^{3,7,8,9}$ The intensity of the $v(\mathrm{C} \equiv \mathrm{N})$ decreased as the nitrile was moved from the 4- to the 3- to the 2- positions for the 4-cyanopyridines, 3-cyanopyridines and 2cyanopyridines, respectively, on silver electrodes. This was due to the interaction of the nitrile moiety with the metal surface. As the molecule tends to a flat-on orientation with respect to the metal surface, the intensity of $v(C \equiv N)$ is lowered. Thus the variation in the intensity of the $v(C \equiv N)$ would give us a clue about the orientation of the adsorbate with respect to the surface of the metal. In previous studies it was assumed that adsorption was occurring primarily through the lone pair of electrons of the nitrogen atom in the aromatic ring. ${ }^{3,7,8,9}$

It is proposed that the cyanopyridines can orient themselves with respect to the surface as shown in Figure 2.1. In the end-on orientation, the adsorbate can orient itself in two different ways. It can orient itself such that the interaction to the surface of the metal is through the lone pair of electrons on the nitrogen atom of the aromatic ring and the $\mathrm{C} \equiv \mathrm{N}$ lies away from the surface. Alternatively, the orientation can be such that the interaction of the adsorbate is through lone pair of electrons on the nitrogen atom of the $\mathrm{C} \equiv \mathrm{N}$ group and the nitrogen atom of the aromatic ring lies away from the surface. The former orientation will cause the frequency of the $\mathrm{C} \equiv \mathrm{N}$ band move to lower wavenumbers and the latter orientation will cause the $\mathrm{C} \equiv \mathrm{N}$ band to move to higher wavenumbers. In the 


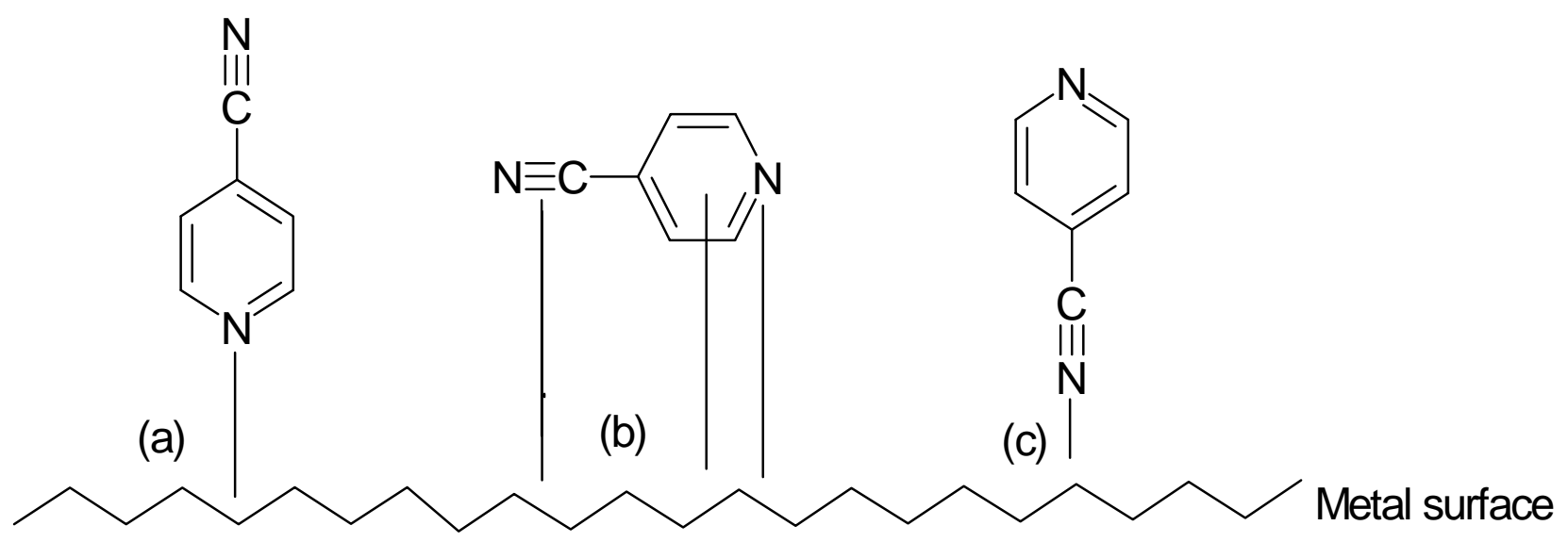

Figure 2.1 Orientation of 4- cyanopyridine on metal surface (a) end-on orientation through aromatic nitrogen (b) flat-on orientation (c) end-on orientation through nitrile nitrogen. A 3-dimensional display of the molecule can show the flat-on orientation of the molecule parallel to the surface. 
flat-on orientation, the molecule lies parallel to the surface and the interaction can occur through the nitrogen atom of the aromatic ring, the nitrogen atom the of $\mathrm{C} \equiv \mathrm{N}$ group, and the $\prod$-cloud of the aromatic ring. This will cause the frequency of the $\mathrm{C} \equiv \mathrm{N}$ band to move to lower wavenumbers. Thus the frequency of the $\mathrm{C} \equiv \mathrm{N}$ band can tell us about the orientation of the adsorbate on the metal surfaces. Apart from the frequency of the $\mathrm{C} \equiv \mathrm{N}$ bands, the shift of the ring breathing modes [near $\left.1000 \mathrm{~cm}^{-1}\right], v(C=C)\left[\right.$ near $\left.1600 \mathrm{~cm}^{-1}\right]$ and $\beta(\mathrm{CH})\left[\right.$ near $1200 \mathrm{~cm}^{-1}$ ] to higher wavenumbers tells us that the adsorption is through the lone pair of electrons on the nitrogen atom.

The shift of $v(\mathrm{C} \equiv \mathrm{N})$ upon adsorption onto the metal surface can be explained in terms of the interaction of the bonding and anti-bonding orbitals of the nitrogen and the metal surface. When the molecule adsorbs parallel to the metal surface, the interaction occurs between the metal surface and the $\mathrm{C} \equiv \mathrm{N}$ bond and through the $\Pi$ system of the aromatic ring. The interaction is through the donation of $\Pi$-orbitals of the lone pair of electrons and through the $\Pi^{*}$ antibonding orbitals of the metal. When the interaction is through the $\Pi$ orbitals, there is weakening of the $\mathrm{C} \equiv \mathrm{N}$ bond. This causes the value of $\nu(C \equiv N)$ to move towards lower frequencies when it gets adsorbed in a flat-on orientation.

When the orientation is end-on, interaction occurs between the $\sigma$-bonding orbital of the lone pair of electrons of nitrogen atom of the nitrile group and the $\sigma^{*}$-antibonding orbital of the metal. Interaction through $\sigma$-bonds is weak and strengthens the $\mathrm{C} \equiv \mathrm{N}$ bond. This causes the $v(\mathrm{C} \equiv \mathrm{N})$ frequency to shift to higher frequency when adsorbed onto the metal surface through end-on orientation. 
When the adsorption occurs through the lone pair of electrons of the nitrogen atom of the aromatic ring, interactions occurs through the $\sigma$-orbital of the nitrogen atom and the $\sigma^{*}$ antibonding orbital of the metal. The conjugation is affected in the aromatic ring due to the donation of electrons. The $\mathrm{C} \equiv \mathrm{N}$ bond is weakly coupled to conjugation and is weakened to only a small extent but not as much as when compared to flat-on orientation. This causes its frequency value to move downwards by only a few wavenumbers.

In our studies, we have collected the SERS spectra of cyanopyridines (CP) and 4 biphenylcarbonitrile (4BPN) over a wide range of concentrations adsorbed on gold colloids, and aminomethylpyridines (AMP) adsorbed on copper colloids. Earlier studies reported that the species adsorbed on the metal surface changed as the potential applied to the electrode surface was varied. ${ }^{10}$ This situation is analogous to the study of adsorbates of varying concentrations adsorbed onto the metal surface where the adsorbate orientation changes. Hence we studied the surface enhancement of adsorbates over a wide range of concentrations on metal colloids to understand the orientation of the adsorbates on the metal surface. At higher concentration, steric effects would play a vital role forcing part of the molecule to change their orientation. ${ }^{7,9,11}$ It was also reported that at different applied potentials the concentration of the adsorbate on the surface changed and the orientation changed between flat-on and end-on orientations. ${ }^{7,911}$ This caused selected vibrational modes to change from parallel to perpendicular relative to the metal surface resulting in an increase in SER effect observed for those motions. 


\subsection{Experimental}

\subsubsection{Colloid Preparation}

The preparation of the gold colloid began with the dissolution of $\mathrm{HAuCl}_{4}$ (Aldrich, $99.99 \%$ ) (240mg) in $500 \mathrm{~mL}$ of water which was then heated to boiling. ${ }^{12}$ A solution of $1 \% \mathrm{w} / \mathrm{w}$ sodium citrate (Aldrich, 99\%) (50 ml) was added. Immediately after the addition of the sodium citrate the solution changed from a pale to a bright yellow color and then to a dark red wine color (absorption band at $523 \mathrm{~nm}$ ). ${ }^{13}$ The solution was maintained at boiling for 2 hours. Raman samples were prepared by adding the adsorbate $(0.3 \mathrm{~mL}$ of stock solution ranging from $2 \times 10^{-2} \mathrm{M}$ to $1 \times 10^{-5} \mathrm{M}$ ) to $2.7 \mathrm{~mL}$ of the gold colloid solution in a disposable borosilicate glass culture tube. The concentrations of all adsorbates in the stock solution and in the experimental solution are given in Table 2.1. The color changed to a dark violet/purple with absorption maxima at $563 \mathrm{~nm}$ indicative of aggregation due to the presence of the adsorbate. The SER spectra were collected starting 80 minutes after the addition of the adsorbate.

The preparation of the copper colloids is based on the borohydride reduction of $\mathrm{Cu}^{2+} .^{14}$ An aqueous solution of copper (II) sulfate (Aldrich Chemical Co., Milwaukee, WI; 99.99\%) (2 $\left.\times 10^{-2} \mathrm{M}, 0.15 \mathrm{~mL}\right)$ was added to a trisodium citrate solution (Aldrich; 99\%) $\left(2.8 \times 10^{-3} \mathrm{M}, 2.0 \mathrm{~mL}\right)$ followed by the addition of a freshly prepared solution of sodium borohydride (Aldrich; 99\%) $\left(2 \times 10^{-2} \mathrm{M}, 1.0 \mathrm{~mL}\right)$ in $1.9 \times 10^{-2} \mathrm{M}$ sodium hydroxide. All colloidal solutions were prepared in disposable borosilicate glass culture tubes. The colloid, which starts as a pale yellow-brown color becomes dark reddish-brown. The red 


\begin{tabular}{|l|l|l|}
\hline Species & $\begin{array}{l}\text { Gold Colloid (species } \\
\text { concentration in the } \\
\text { solution) }\end{array}$ & $\begin{array}{l}\text { Copper Colloid (species } \\
\text { concentration in the } \\
\text { solution) }\end{array}$ \\
\hline Adsorbate & $10^{-6} \mathrm{M}$ to $2 \times 10^{-2} \mathrm{M}$ & $8.7 \times 10^{-7} \mathrm{M}$ to $1.7 \times 10^{-2} \mathrm{M}$ \\
\hline Tetrachloroaurate (IV) & $1.3 \times 10^{-3} \mathrm{M}$ & - \\
\hline Copper (II) sulfate & - & $8.7 \times 10^{-4} \mathrm{M}$ \\
\hline Sodium hydroxide & - & $5.5 \times 10^{-3} \mathrm{M}$ \\
\hline Trisodium citrate & $3.1 \times 10^{-3} \mathrm{M}$ & $1.6 \times 10^{-3} \mathrm{M}$ \\
\hline Sodium borohydride & - & $5.8 \times 10^{-3} \mathrm{M}$ \\
\hline
\end{tabular}

Table 2.1 Final concentrations in solution of the species used for the preparation of gold colloid and copper colloid.

color is indicative of particle sizes ranging from 10 to $20 \mathrm{~nm}$ and gives rise to an absorption band at $564 \mathrm{~nm} \cdot{ }^{13}$ After the colloid was allowed to age for two hours, an aqueous solution of the 4-AMP (Aldrich; $98 \%)(0.30 \mathrm{~mL}$ of stock solution ranging from $0.2 \mathrm{M}$ to $1 \times 10^{-5} \mathrm{M}$ ) was added to the culture tube. Upon addition of 4-AMP, the colloid changed to a dark gray-brown color due to aggregation and had an absorption band at 570 nm. The excess borohydride provides a buffer against oxidation of the copper particles. The high $\mathrm{pH}$ of the colloid solution stabilizes the borohydride ions, while the trisodium 
citrate minimizes colloid precipitation. The copper colloids are stable for approximately 24 hours if stored in a well-stoppered container. Data collection of the SER spectra of the aminomethylpyridines adsorbed onto copper colloids was begun 80 minutes after the addition of the adsorbate solution to the colloid.

\subsubsection{Spectra Collection}

Raman data was collected using a Lexel Ramanion $\mathrm{Kr}^{+}$laser operating at $647.1 \mathrm{~nm}$. The power at the sample was $20 \mathrm{~mW}$. A Spex Industries (Edison, NJ) Triplemate system equipped with a 600 -groves $/ \mathrm{mm}$ grating and an Oxford CCD detector operating at $143 \mathrm{~K}$ was used for detection. A $90^{\circ}$ geometry was used for collection of scattered radiation. The spectrum of each sample was collected as four different spectra. They were collected as four different windows. Each window covered a frequency range of $550 \mathrm{~cm}^{-1}$. The different windows were then joined together using SpectraSolve software.The instrument was calibrated with indene and benzonitrile and all the wavenumbers are believed to be accurate to $5 \mathrm{~cm}^{-1}$. The experiments were repeated to check for the reproducibility. The standard deviations for each peak position were calculated from three sets of experimental data to check for the precision. The average standard deviation for the goldcyanopyridine, gold-biphenylcarbonitrile and copper-aminomethylpyridine systems were $\pm 3.1, \pm 2.5$ and \pm 4.7 wavenumbers respectively. The absorption spectra were recorded with a Perkins Elmer (Norwalk, CT) Lambda-6 UV-VIS spectrophotometer. 


\subsection{Results and Discussion}

\subsubsection{Study of orientation of cyanopyridines on gold colloid}

4-Cyanopyridine, 3-cyanopyridine and 2-cyanopyridine were adsorbed on gold colloids. The concentrations of the cyanopyridines were varied from $2 \times 10^{-2} \mathrm{M}$ to $1 \times 10^{-6} \mathrm{M}$. Concentration studies were performed to investigate the orientation of the cyanopyridines on the gold colloids.

\section{4-cyanopyridines on gold colloids}

The SER spectra of 4-cyanopyridine adsorbed on gold colloids are shown in Figure 2.2. The observed frequencies and the tentative assignment of the bands are presented in Table 2.2. The frequency of the $v(\mathrm{C} \equiv \mathrm{N})$ band is shifted down for all concentrations of 4cyanopyridines with respect to the free molecule. ${ }^{15}$ This suggests the orientation is endon for all concentrations of 4-cyanopyridines and the interaction is through the lone pair of electrons of the nitrogen atom of the aromatic ring. The shift of the ring breathing mode at $1000 \mathrm{~cm}^{-1}$, the $\beta(\mathrm{CH})$ mode at $1201 \mathrm{~cm}^{-1}$ and $v(\mathrm{C}=\mathrm{C})$ mode at $1597 \mathrm{~cm}^{-1}$ towards higher wavenumber further confirms that the interaction is through the nitrogen atom of the aromatic ring. ${ }^{15,16}$

There are certain striking features regarding the intensity of the bands for various concentrations. The intensity of the $\mathrm{C} \equiv \mathrm{N}$ band is the lowest for the $1 \times 10^{-6} \mathrm{M}$, increases for $1 \times 10^{-4} \mathrm{M}$, reaches the highest for $1 \times 10^{-3} \mathrm{M}$ and again decreases for $1 \times 10^{-2} \mathrm{M}$ and $2 \times 10^{-2} \mathrm{M}$ (but the intensity is not as low as for $1 \times 10^{-6} \mathrm{M}$ and $1 \times 10^{-4} \mathrm{M}$ ). The intensity of the ring breathing mode remains the lowest for $1 \times 10^{-6} \mathrm{M}, 1 \times 10^{-4} \mathrm{M}$ and $1 \times 10^{-3} \mathrm{M}$ and reaches the highest for $1 \times 10^{-2} \mathrm{M}$ and $2 \times 10^{-2} \mathrm{M}$. The $\beta(\mathrm{CH})$ mode at $1201 \mathrm{~cm}^{-1}$ is the lowest for the 
$1 \times 10^{-6} \mathrm{M}$ concentration and gradually increases for $1 \times 10^{-4} \mathrm{M}, 1 \times 10^{-3} \mathrm{M}, 1 \times 10^{-2} \mathrm{M}$ and comes down for $2 \times 10^{-2} \mathrm{M}$. The intensity of the $\mathrm{v}(\mathrm{C}=\mathrm{C})$ band occurring at $1597 \mathrm{~cm}^{-1}$ is the lowest for $1 \times 10^{-6} \mathrm{M}$, increases for $1 \times 10^{-4} \mathrm{M}$ and reaches the highest for $1 \times 10^{-3} \mathrm{M}, 1 \times 10^{-2} \mathrm{M}$ and $2 \times 10^{-2} \mathrm{M}$. These changes in intensity suggest that even though the overall orientation remains end-on through the nitrogen atom of the aromatic ring, there is still a gradual change in the orientation of the 4-cyanopyridines. We suggest that the orientation of 4cyanopyridines follows the trend as shown in Figure 2.3.

\section{3-cyanopyridines on gold colloids:}

The SER spectra of 3-cyanopyridine adsorbed on gold colloids for concentrations ranging from $2 \times 10^{-2} \mathrm{M}$ to $1 \times 10^{-5} \mathrm{M}$ is shown in Figure 2.4(i) and Figure 2.4(ii). The observed frequencies and the tentative band assignments are presented in Table 2.3. The striking feature of the spectra of 3-cyanopyridines on gold colloids compared to the spectra of the molecules of 4-cyanopyridines on gold colloids is the decrease in the intensity of the $v(\mathrm{C} \equiv \mathrm{N})$ band. This is because of the closer proximity of the $\mathrm{C} \equiv \mathrm{N}$ moiety to the metal surface. As the $\mathrm{C} \equiv \mathrm{N}$ group moves closer to the metal surface, the interaction of the cyano group with the metal surface increases and the intensity of $v(\mathrm{C} \equiv \mathrm{N})$ decreases.

The frequency of $v(\mathrm{C} \equiv \mathrm{N})$ is lowered for all concentrations of 3-cyanopyridines on the metal surface compared to the free molecule. Since the shift is only by a few wavenumbers, it suggests that the orientation is end-on with the primary interaction occurring through the lone pair of electrons of the nitrogen atom of the aromatic ring. The ring breathing mode at $976 \mathrm{~cm}^{-1}$, the $\beta(\mathrm{CH})$ mode at $1357 \mathrm{~cm}^{-1}$ and the $v(\mathrm{C}=\mathrm{C})$ mode 


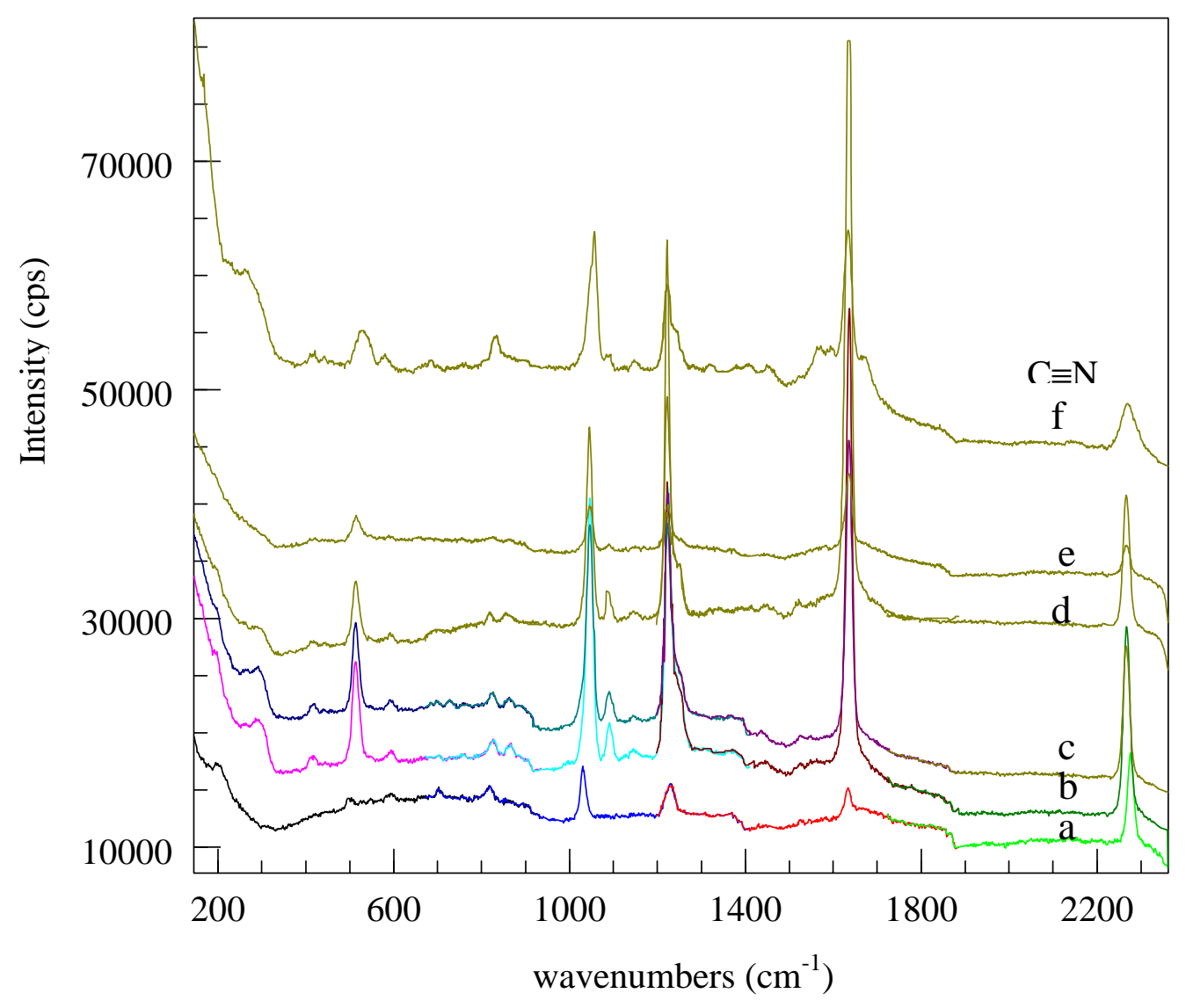

Figure 2.2 Raman Spectra of 4-cyanopyridine and SERS of 4-cyanopyridine of various concentrations adsorbed on gold colloids (a) Parent 4-cyanopyridine, (b) Au/2x10-2 M 4-

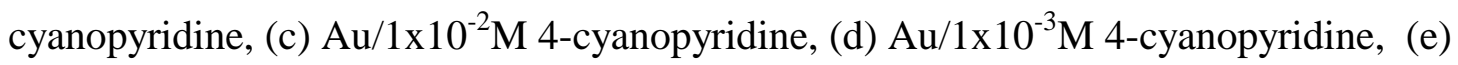
$\mathrm{Au} / 1 \times 10^{-4} \mathrm{M}$ 4-cyanopyridine, (f) $\mathrm{Au} / 1 \times 10^{-6} \mathrm{M}$ 4-cyanopyridine 
Table 2.2 Raman frequencies of neat 4 cyanopyridines(4-CP) and SERS frequencies of various concentrations of 4-cyanopyridine adsorbed on Gold colloids. Concentration of 4 cyanopyridines adsorbed on the colloid ranges from $2 \times 10^{-2} \mathrm{M}$ to $1 \times 10^{-6} \mathrm{M}$

\begin{tabular}{|l|l|l|l|l|l|l|}
\hline $\begin{array}{l}\text { Band } \\
\text { Assignment }\end{array}$ & $4 \mathrm{CP}$ & $\begin{array}{l}\mathrm{Au} / 2 \times 10^{-2} \mathrm{M} \\
4 \mathrm{CP}\end{array}$ & $\begin{array}{l}\mathrm{Au} / 1 \times 10^{-2} \mathrm{M} \\
4 \mathrm{CP}\end{array}$ & $\mathrm{Au} / 10^{-3} \mathrm{M} 4 \mathrm{CP}$ & $\mathrm{Au} / 10^{-4} \mathrm{M} 4 \mathrm{CP}$ & $\mathrm{Au} / 10^{-6} \mathrm{M} 4 \mathrm{CP}$ \\
\hline$\gamma(\mathrm{C}=\mathrm{N})$ & 169 & & & & & \\
\hline $\mathrm{C}=\mathrm{N}$ sensitive & - & 415.4 & 415.4 & 415.4 & 415.4 & 415.4 \\
\hline $\mathrm{C}=\mathrm{N}$ sensitive & - & - & 446.1 & 446.1 & - & 446.1 \\
\hline $\mathrm{C}=\mathrm{N}$ sensitive & 492.3 & 507.7 & 515.4 & 507.7 & 500 & - \\
\hline $\mathrm{C}=\mathrm{N}$ sensitive & 530.8 & - & - & - & - & 523.1 \\
\hline$\varnothing(\mathrm{CC})$ & 547 & 563 & 547 & 563 & 563 & 547 \\
\hline$\alpha(\mathrm{CCC})$ & - & - & 661.5 & - & 661.5 & - \\
\hline$\alpha(\mathrm{CCC})$ & - & 676.9 & 676.9 & - & - & 676.9 \\
\hline $\mathrm{C}=\mathrm{N}$ sensitive & 700 & 700 & 692.3 & 692.3 & & \\
\hline $\mathrm{C}=\mathrm{N}$ sensitive & - & - & 715.4 & - & - & 761.5 \\
\hline $\mathrm{C}=\mathrm{N}$ sensitive & - & 753.8 & 746.1 & - & - & - \\
\hline $\mathrm{C}=\mathrm{N}$ sensitive & - & 815.4 & 815.4 & 815.4 & 823.1 & 823.1 \\
\hline$\gamma(\mathrm{CH})$ & 807.7 & - & 776.9 & & & - \\
\hline
\end{tabular}




\begin{tabular}{|c|c|c|c|c|c|c|}
\hline$\gamma(\mathrm{CH})$ & 846.1 & - & - & - & - & - \\
\hline$\gamma(\mathrm{CH})$ & 892.3 & - & - & - & - & - \\
\hline$\gamma(\mathrm{CH})$ & 946.1 & - & - & - & - & - \\
\hline Ring breathing & 1000 & 1004 & 1011 & 1011 & 1011 & 1011 \\
\hline$\beta(\mathrm{CH}), \alpha(\mathrm{CC})$ & - & 1092.3 & 1084.6 & 1092 & 1084.6 & 1084.6 \\
\hline$\beta(\mathrm{CH}), \alpha(\mathrm{CC})$ & 1107.7 & 1146.1 & 1138.5 & 1146 & 1146.1 & 1146.1 \\
\hline$\beta(\mathrm{CH}), \alpha(\mathrm{CC})$ & 1201 & 1208 & 1208 & 1208 & 1215 & 1215 \\
\hline$\beta(\mathrm{CH})$ & - & 1257 & - & 1257 & 1257 & 1264.6 \\
\hline$\beta(\mathrm{CH})$ & 1300 & 1300 & - & - & - & 1323.1 \\
\hline$\beta(\mathrm{CH})$ & 1361 & 1361.5 & 1361.5 & - & - & 1376.9 \\
\hline $\mathrm{v}(\mathrm{C}=\mathrm{C}, \mathrm{CN})$ & - & 1400 & 1430.8 & - & - & 1415 \\
\hline$v(C=C)$ & - & 1450 & 1477 & - & - & 1442 \\
\hline$v(C=C)$ & - & 1515.4 & 1515.4 & 1515.4 & - & - \\
\hline$v(C=C)$ & 1530 & 1530 & 1530 & 1530 & - & 1561.5 \\
\hline$v(C=C)$ & 1584 & 1546 & 1546 & 1546 & - & 1592.3 \\
\hline $\mathrm{v}(\mathrm{C}=\mathrm{C})$ & 1597 & 1602 & 1602 & 1602 & 1611 & 1606 \\
\hline$v(\mathrm{C} \equiv \mathrm{N})$ & 2235 & 2231 & 2224 & 2224 & 2227 & 2231 \\
\hline
\end{tabular}


At $1580 \mathrm{~cm}^{-1}$ are all shifted to higher wavenumbers for all concentrations of 3cyanopyridine.This suggests the interaction occurs through the lone pair of electrons of the nitrogen atom in the aromatic ring.

There are differences in the intensities of the $v(C \equiv N)$ band for various concentrations of 3-cyanopyridines. The intensity is high for $2 \times 10^{-2} \mathrm{M}$ and $1 \times 10^{-2} \mathrm{M}$, is lowered for the $1 \times 10^{-3} \mathrm{M}$ concentration, is strongest for $1 \times 10^{-4} \mathrm{M}$ and is absent for $1 \times 10^{-6} \mathrm{M}$. This suggests the interaction of the cyano group of 3- cyanopyridine with the surface is the weakest for $2 \times 10^{-2} \mathrm{M}, 1 \times 10^{-2} \mathrm{M}$ and $1 \times 10^{-4} \mathrm{M}$, strong for $1 \times 10^{-3} \mathrm{M}$ and is the strongest for $1 \times 10^{-6} \mathrm{M}$. Based on steric effects, it is possible to conclude that for $2 \times 10^{-2} \mathrm{M}$ and $1 \times 10^{-2} \mathrm{M}$, the number of molecules adsorbed to the metal surface is high which forces the molecules to align perpendicular to the surface and decreases the interaction of the $\mathrm{C} \equiv \mathrm{N}$ moiety with the metal surface. For $1 \times 10^{-6} \mathrm{M}$, the number of molecules on the surface is lowered and the $v(\mathrm{C} \equiv \mathrm{N})$ group moves close to the metal surface and hence the interaction becomes the strongest at this concentration. Hence the signal for $\mathrm{C} \equiv \mathrm{N}$ is the weakest in the SER spectra for $1 \times 10^{-6} \mathrm{M}$ concentrations of 3-cyanopyridine and is not observed.

The spectra for various concentrations are different and hence the orientation of the molecule is different at different concentrations. The shift of $v(\mathrm{C} \equiv \mathrm{N})$ towards lower wavenumbers for all concentrations and the shift of the ring breathing modes, $\beta(\mathrm{CH})$ and $v(C=C)$ towards higher wavenumbers for all concentrations suggest that the overall interaction of 3-cyanopyridines on gold colloids is end-on through the nitrogen atom of the aromatic ring. However the difference in spectra at various concentrations suggest that there is a gradual slight shift in the orientation with respect to the surface retaining 


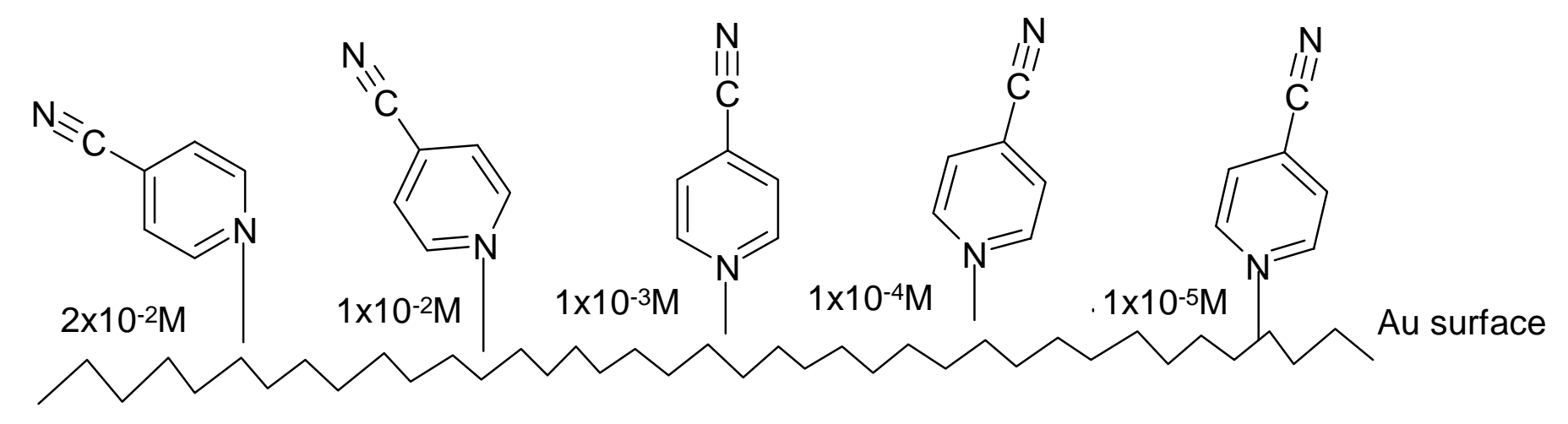

Figure 2.3 Suggested gradual change in the orientation of 4-cyanopyridines on gold colloid with change in concentration of 4cyanopyridine 


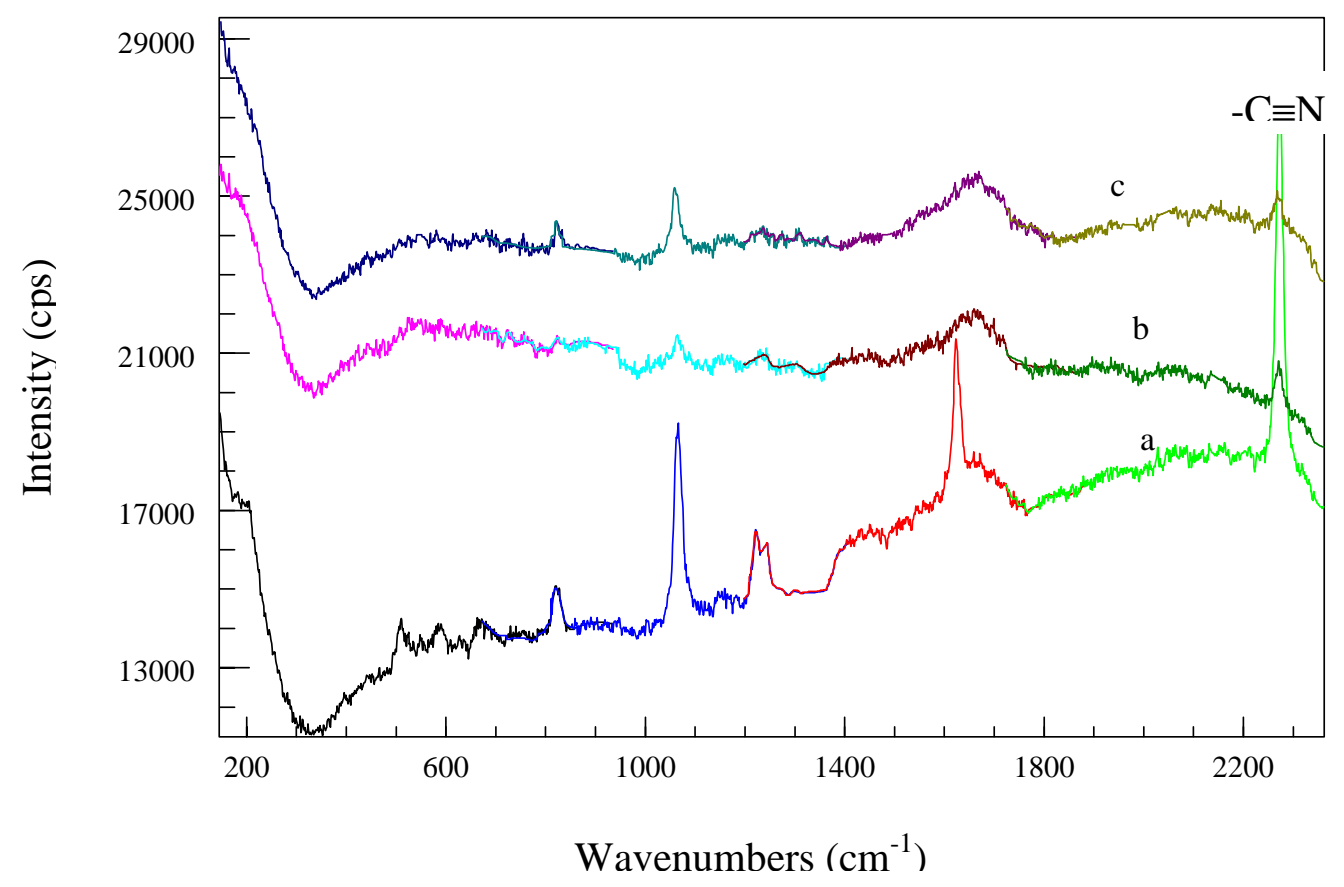

Figure 2.4(i) Raman spectra of 3-cyanopyridine and SERS of 3-cyanopyridine of various concentrations adsorbed on gold colloid (a) Parent 3-cyanopyridine (b) Au/ $2 \times 10^{-2} \mathrm{M} 3-$ cyanopyridine (c) $\mathrm{Au} / 1 \times 10^{-2} \mathrm{M} 3$-cyanopyridine 


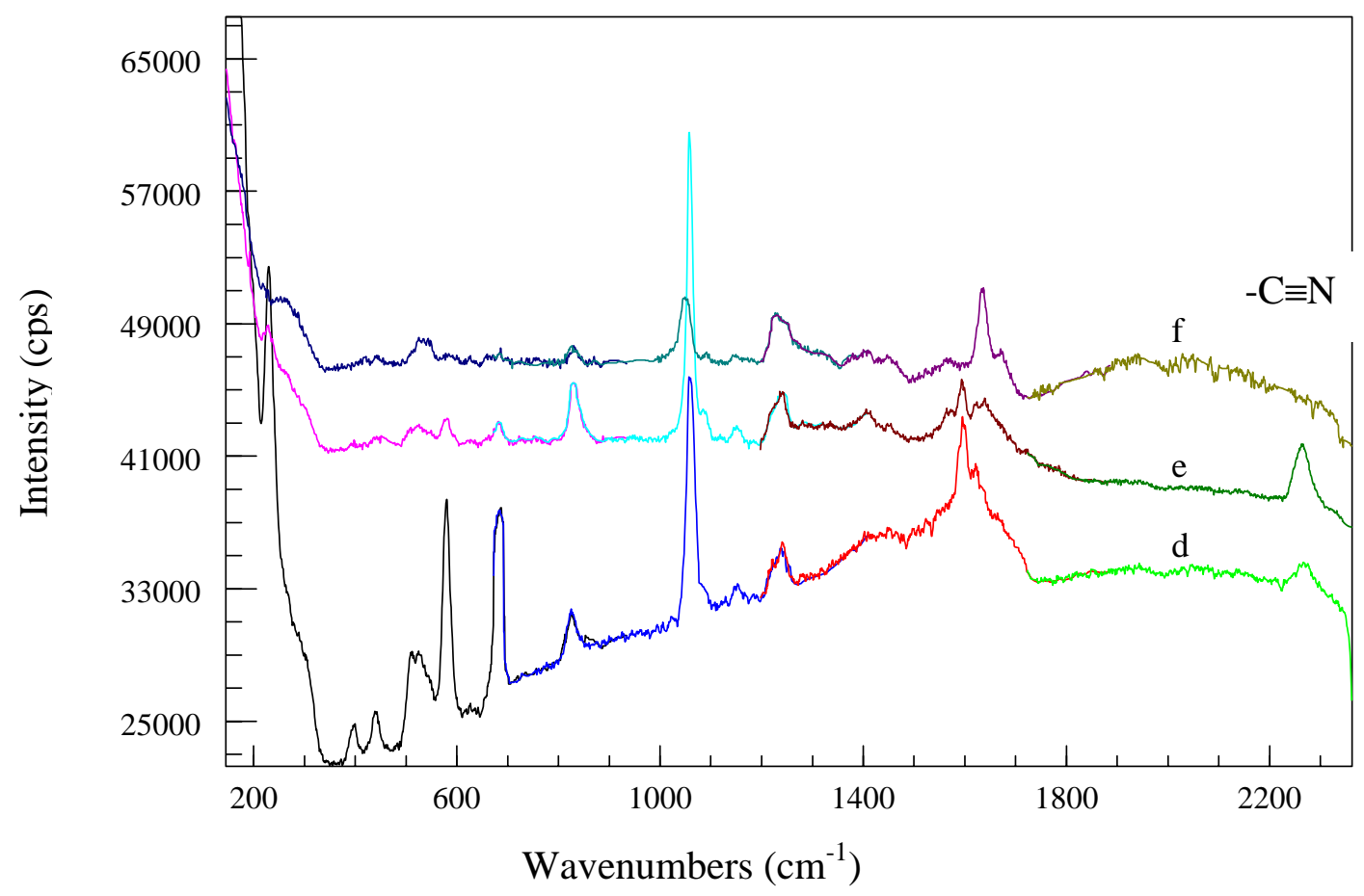

Figure 2.4 (ii) SERS of 3-cyanopyridines of various concentrations adsorbed on gold

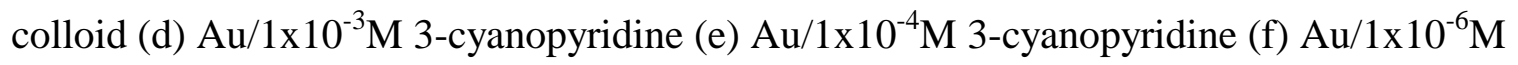
3-cyanopyridine 
Table 2.3 Raman frequencies of neat 3-cyanopyridines(3-CP) and SERS frequencies of various concentrations of 3-cyanopyridine adsorbed on Gold colloids. Concentration of 3-cyanopyridines adsorbed on the colloid ranges from $2 \times 10^{-2} \mathrm{M}$ to $1 \times 10^{-6} \mathrm{M}$

\begin{tabular}{|c|c|c|c|c|c|c|}
\hline Band Assignment & $3 \mathrm{CP}$ & $\begin{array}{l}\mathrm{Au} / 2 \times 10^{-2} \mathrm{M} \\
3 \mathrm{CP}\end{array}$ & $\begin{array}{l}\mathrm{Au} / 1 \times 10^{-2} \mathrm{M} \\
3 \mathrm{CP}\end{array}$ & $\mathrm{Au} / 10^{-3} \mathrm{M} 3 \mathrm{CP}$ & $\mathrm{Au} / 10^{-4} \mathrm{M} 3 \mathrm{CP}$ & $\mathrm{Au} / 10^{-6} \mathrm{M} 3 \mathrm{CP}$ \\
\hline $\mathrm{C}=\mathrm{N}$ sensitive, $\delta(\mathrm{CN})$ & 176.7 & - & 161.7 & 190.7 & 205 & 183 \\
\hline$\phi(\mathrm{CC}), \mathrm{C}=\mathrm{N}$ sensitive, $\gamma(\mathrm{CN})$ & 400 & - & - & 400 & 385 & 407 \\
\hline$\phi(\mathrm{CC}), \mathrm{C}=\mathrm{N}$ sensitive, $\gamma(\mathrm{CN})$ & 442 & 428 & 442 & 442 & 442 & 428 \\
\hline $\mathrm{C}=\mathrm{N}$ sensitive, $\delta(\mathrm{CN})$ & 465 & 465 & 457 & - & 465 & - \\
\hline$\phi(\mathrm{CC}), \mathrm{C}=\mathrm{N}$ sensitive, $\gamma(\mathrm{CN})$ & 500 & 500 & 514 & 514 & 520 & 514 \\
\hline$\phi(\mathrm{CC}), \mathrm{C}=\mathrm{N}$ sensitive, $\gamma(\mathrm{CN})$ & 542 & 542 & 542 & - & - & - \\
\hline$\phi(\mathrm{CC}), \mathrm{C}=\mathrm{N}$ sensitive, $\gamma(\mathrm{CN})$ & 585 & - & 585 & 571 & 575 & 571 \\
\hline$\alpha(\mathrm{CCC})$ & 628 & 628 & - & 620 & 628 & 614 \\
\hline$\alpha(\mathrm{CCC})$ & 657 & & 671 & 671 & 671 & 671 \\
\hline
\end{tabular}




\begin{tabular}{|c|c|c|c|c|c|c|}
\hline $\mathrm{C}=\mathrm{N}$ sensitive & 728 & 742 & - & 714 & 714 & - \\
\hline $\mathrm{C}=\mathrm{N}$ sensitive & 757 & 771 & - & 757 & - & - \\
\hline $\mathrm{C}=\mathrm{N}$ sensitive & 807 & 800 & 807 & 828 & 820 & 820 \\
\hline$\$$ & 885 & 871 & - & 900 & - & - \\
\hline$\$$ & - & - & - & 914 & - & - \\
\hline Ring breathing & 976 & 997 & 997 & 1011 & 1011 & 1004 \\
\hline$\beta(\mathrm{CH})$ & 1085 & - & 1085 & 1071 & 1071 & 1071 \\
\hline$\$$ & 1114 & - & - & - & 114 & 1135 \\
\hline$\beta(\mathrm{CH})$ & 1157 & - & - & 1142 & 1142 & - \\
\hline $\mathrm{C}=\mathrm{N}$ sensitive & 1214 & - & - & - & - & - \\
\hline $\mathrm{C}=\mathrm{N}$ sensitive & 1228 & 1228 & 1228 & 1228 & 1230 & 1228 \\
\hline$\alpha(\mathrm{CCC})$ & 1271 & - & 1271 & - & 1271 & - \\
\hline$\$$ & 1300 & - & 1300 & - & 1314 & 1314 \\
\hline$\beta(\mathrm{CH})$ & 1357 & 1362 & 1365 & 1371 & 1371 & 1365 \\
\hline $\mathrm{v}(\mathrm{C}=\mathrm{C}, \mathrm{CN})$ & 1428 & - & - & 1435 & 1442 & 1435 \\
\hline
\end{tabular}




\begin{tabular}{|l|l|l|l|l|l|l|}
\hline$v(\mathrm{C}=\mathrm{C}, \mathrm{CN})$ & 1457 & - & - & - & - & - \\
\hline$v(\mathrm{C}=\mathrm{C})$ & 1571 & 1585 & - & 1585 & 1585 & 1557 \\
\hline$v(\mathrm{C}=\mathrm{C})$ & 1580 & 1582 & 1582 & 1594 & 1596 & 1594 \\
\hline$v(\mathrm{CN})$ & 2227 & 2224 & 2227 & 2221 & 2224 & - \\
\hline
\end{tabular}


the overall end-on configuration with interaction through the nitrogen atom of the aromatic ring. Based on the results, we suggest the orientation of 3-cyanopyridine on gold colloids is as shown in Figure 2.5.

\section{2-cyanopyridines on gold colloids:}

The spectra are complicated for 2-cyanopyridines because of their strong interaction with the metal surface. The SER spectra of 2-cyanopyridine adsorbed on gold colloids are shown in Figure 2.6(i), 2.6(ii) and 2.6(iii). The observed frequencies and the tentative band assignments are presented in Table 2.4. The prominent feature observed in these spectra is that the $v(\mathrm{C} \equiv N)$ band is no longer intense and the intense bands are the ring breathing mode and the $\beta(\mathrm{CH})$ modes occurring at $1000 \mathrm{~cm}^{-1}$ and $1220 \mathrm{~cm}^{-1}$ respectively. The $v(\mathrm{C} \equiv \mathrm{N})$ band is very weak in the SER spectra even though it is seen in the parent molecule.

The decreased intensity of the $v(\mathrm{C} \equiv \mathrm{N})$ band in the SER spectra is due to the closer proximity of the $\mathrm{C} \equiv \mathrm{N}$ group to the metal surface. The stronger interaction between the $\mathrm{C} \equiv \mathrm{N}$ group and the metal surface leads to a weaker band. The $v(\mathrm{C} \equiv \mathrm{N})$ band is shifted to lower wavenumbers for all concentrations of 2-cyanopyridine on the metal surface. This suggests the orientation is end-on with interaction occurring primarily through the nitrogen atom of the aromatic ring. The ring breathing mode at $1000 \mathrm{~cm}^{-1}$, the $\beta(\mathrm{CH})$ mode at $1221 \mathrm{~cm}^{-1}$ and $v(\mathrm{C}=\mathrm{C})$ at $1593 \mathrm{~cm}^{-1}$ is shifted to higher wavenumber for all concentrations of 2-cyanopyridine. This suggests the interaction is through the nitrogen atom in the aromatic ring as observed for 4-cyanopyridine and 3-cyanopyridine. 


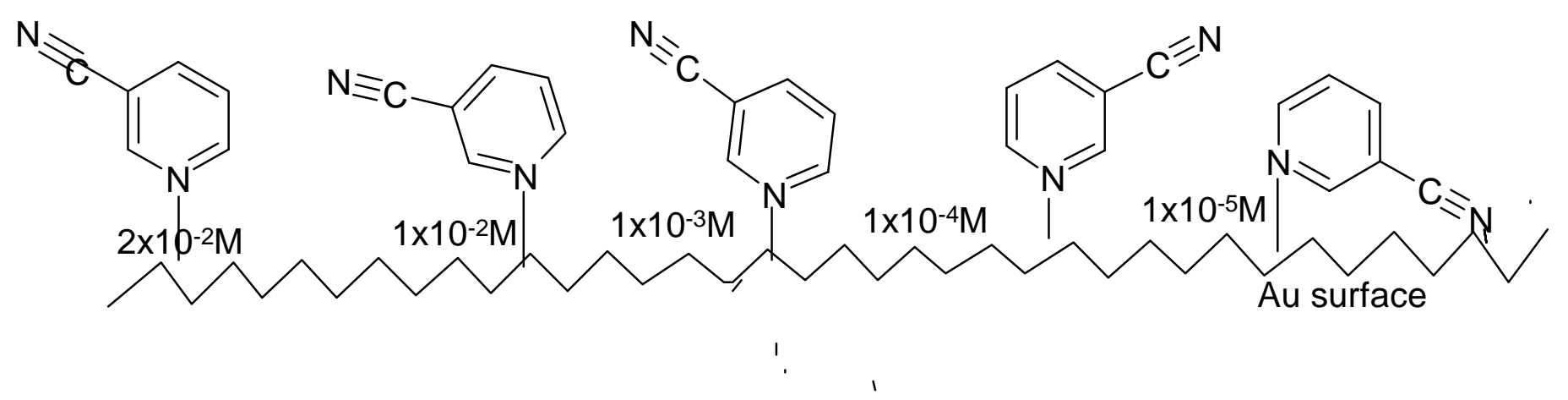

Figure 2.5 Suggested gradual change in orientation of 3-cyanopyridine on gold colloid with change in concentration of 3cyanopyridine 


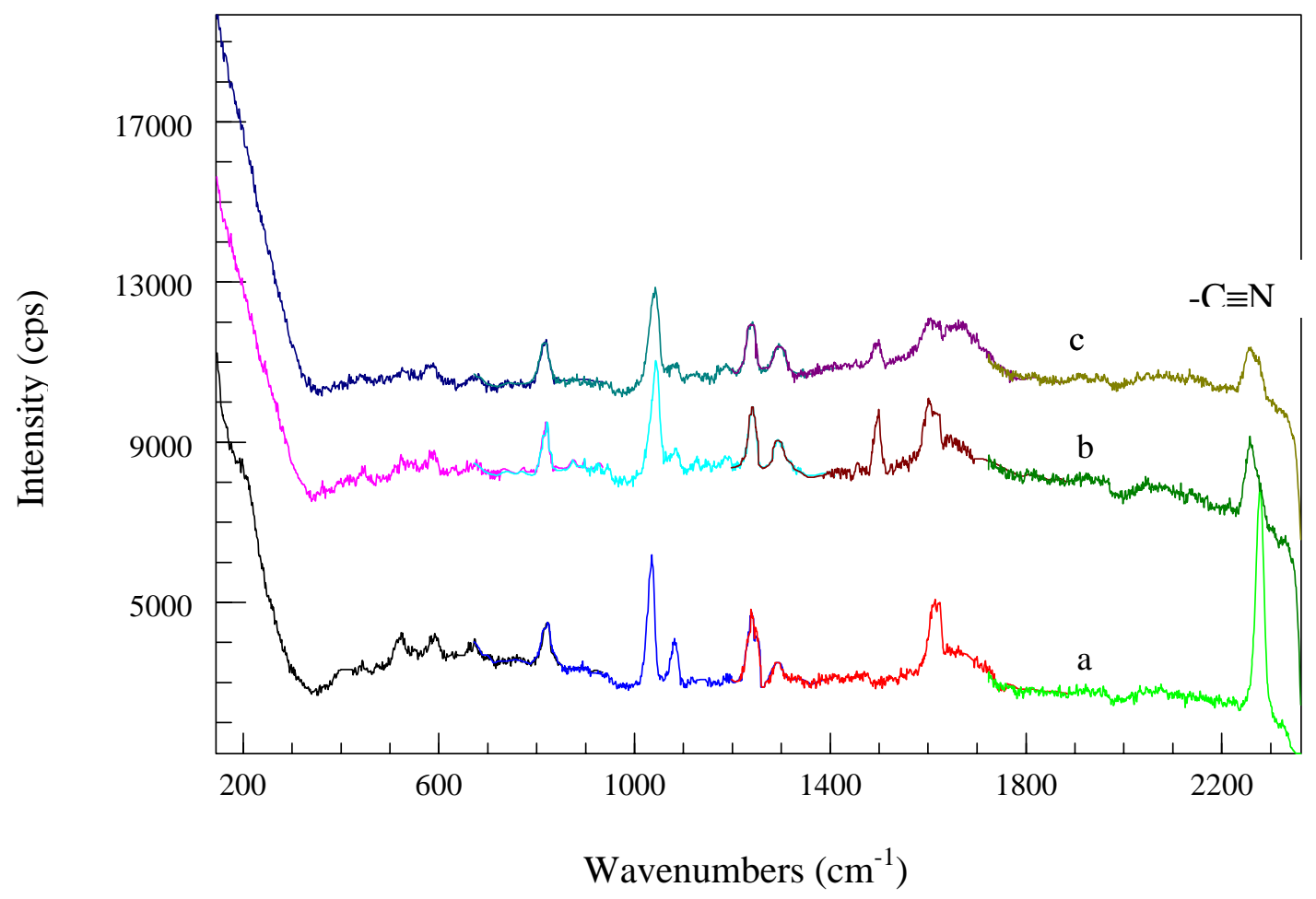

Figure 2.6(i) Raman spectrum of 2-cyanopyridine and SERS of 2-cyanopyridine adsorbed on gold colloids.(a) Parent 2-cyanopyridine (b) Au/2x10-2 M 2-cyanopyridine (c) $\mathrm{Au} / 1 \times 10^{-2} \mathrm{M} 2$-cyanopyridine 


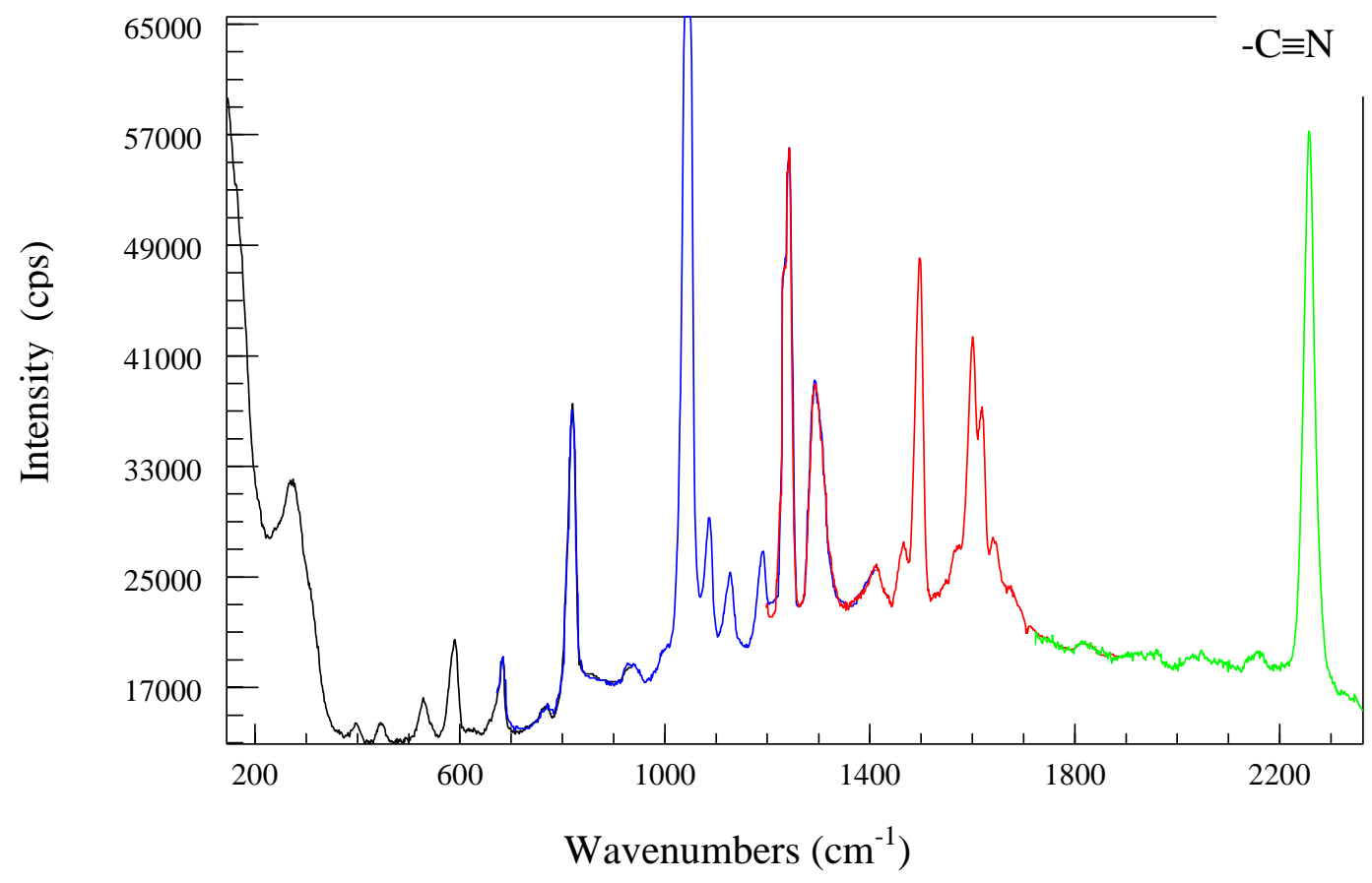

Figure 2.6 (ii) SERS of $\mathrm{Au} / 1 \times 10^{-3} \mathrm{M} 2$-cyanopyridine adsorbed on gold colloid 


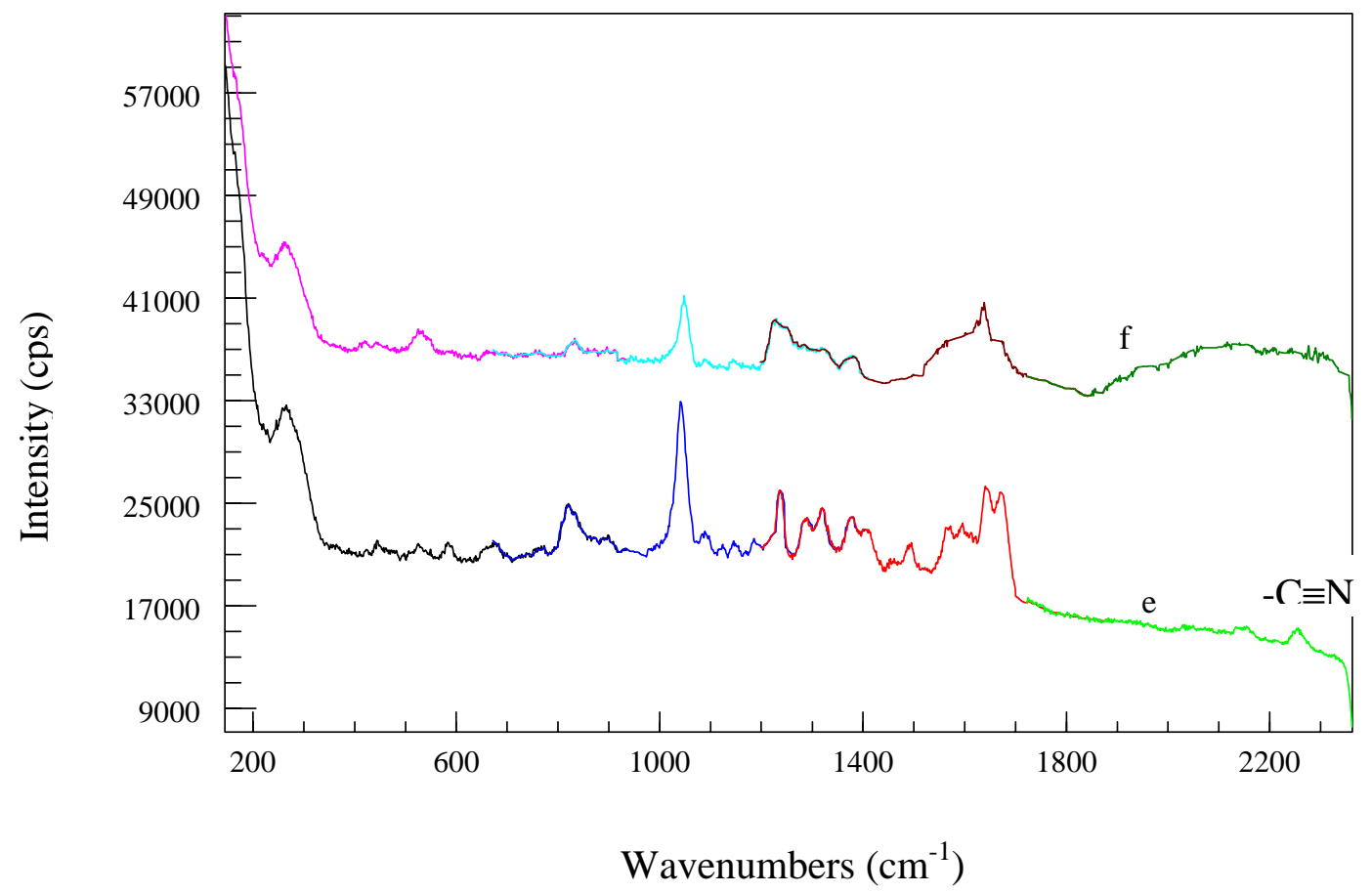

Figure2.6(iii) SERS of 2-cyanopyridine adsorbed on gold colloid.(e) Au/1x $10^{-4} \mathrm{M} 2-$ cyanopyridine (f) $\mathrm{Au} / 1 \times 10^{-6} \mathrm{M}$ 2-cyanopyridine. 
Table 2.4 Raman frequencies of neat 2-cyanopyridine(2-CP) and SERS frequencies of various concentrations of 2-cyanopyridine adsorbed on Gold colloids. Concentration of 2-cyanopyridines adsorbed on the colloid ranges from $2 \times 10^{-2} \mathrm{M}$ to $1 \times 10^{-6} \mathrm{M}$

\begin{tabular}{|c|c|c|c|c|c|c|}
\hline Band Assignment & $2 \mathrm{CP}$ & $\begin{array}{l}\mathrm{Au} / 2 \times 10^{-2} \mathrm{M} \\
2 \mathrm{CP}\end{array}$ & $\begin{array}{l}\mathrm{Au} / 1 \times 10^{-2} \mathrm{M} \\
2 \mathrm{CP}\end{array}$ & $\mathrm{Au} / 10^{-3} \mathrm{M} 2 \mathrm{CP}$ & $\mathrm{Au} / 10^{-4} \mathrm{M} 2 \mathrm{CP}$ & $\mathrm{Au} / 10^{-6} \mathrm{M} 2 \mathrm{CP}$ \\
\hline $\mathrm{C}=\mathrm{N}$ sensitive, $\delta(\mathrm{CN})$ & 162.7 & - & - & - & - & - \\
\hline$\varnothing(\mathrm{CC}, \mathrm{C}=\mathrm{N}$ sensitive, $\gamma(\mathrm{CN})$ & 383 & 418 & - & 395 & - & - \\
\hline $\mathrm{C}=\mathrm{N}$ sensitive, $\delta(\mathrm{CN})$ & 441 & 453 & 465 & 453 & 453 & 418 \\
\hline $\mathrm{C}=\mathrm{N}$ sensitive, $\delta(\mathrm{CN})$ & 523 & 546 & 534 & 534 & 546 & 534 \\
\hline $\mathrm{C}=\mathrm{N}$ sensitive, $\delta(\mathrm{CN})$ & 581 & 604 & 593 & 593 & 581 & 593 \\
\hline$\alpha(\mathrm{CCC})$ & 662 & 686 & 674 & 686 & 686 & 674 \\
\hline $\mathrm{C}=\mathrm{N}$ sensitive & 814 & 825 & 814 & 814 & 825 & 825 \\
\hline Ring breathing & 1000 & 1035 & 1035 & 1023 & 1035 & 1023 \\
\hline$\beta(\mathrm{CH})$ & 1116 & 1139 & 1127 & 1127 & 1127 & 1139 \\
\hline
\end{tabular}




\begin{tabular}{|c|c|c|c|c|c|c|}
\hline$\beta(\mathrm{CH})$ & 1174 & 1162 & 1186 & 1186 & 1186 & - \\
\hline$\beta(\mathrm{CH})$ & 1221 & 1244 & 1232 & 1244 & 1244 & 1232 \\
\hline $\mathrm{C}=\mathrm{N}$ sensitive & 1238 & - & - & - & - & 1255 \\
\hline$\beta(\mathrm{CH})$ & 1279 & - & 1290 & - & 1279 & - \\
\hline$\beta(\mathrm{CH})$ & - & 1302 & - & 1302 & 1314 & 1325 \\
\hline $\mathrm{V}(\mathrm{C}=\mathrm{C}, \mathrm{CN})$ & 1465 & - & 1488 & 1465 & 1488 & 1465 \\
\hline $\mathrm{V}(\mathrm{C}=\mathrm{C})$ & - & 1500 & - & - & - & 1523 \\
\hline $\mathrm{V}(\mathrm{C}=\mathrm{C})$ & 1565 & 1565 & 1565 & 1588 & 1588 & 1588 \\
\hline $\mathrm{V}(\mathrm{C}=\mathrm{C})$ & - & - & - & - & 1651 & 1651 \\
\hline $\mathrm{V}(\mathrm{C}=\mathrm{C})$ & 1512 & - & - & - & - & - \\
\hline $\mathrm{V}(\mathrm{C}=\mathrm{C})$ & 1593 & 1593 & 1593 & 1593 & 1593 & 1616 \\
\hline $\mathrm{V}(\mathrm{C} \equiv \mathrm{N})$ & 2216 & 2205 & 2205 & 2199 & 2199 & - \\
\hline
\end{tabular}


The intensity of $v(\mathrm{C} \equiv \mathrm{N})$ is high for $2 \times 10^{-2} \mathrm{M}$ and decreases for concentration $1 \times 10^{-2} \mathrm{M}$, reaches the highest for $1 \times 10^{-3} \mathrm{M}$ and again decreases for $1 \times 10^{-4} \mathrm{M}$ and is absent for the $1 \times 10^{-6} \mathrm{M}$ concentration. This feature can be explained based on the number of molecules adsorbed on the metal surface and the closer proximity of $\mathrm{C} \equiv \mathrm{N}$ moiety with respect to the metal surface. At $2 \times 10^{-2} \mathrm{M}$, the number of molecules adsorbed on the metal surface is high and some of the molecules are pushed apart increasing the distance between the $\mathrm{C} \equiv \mathrm{N}$ moiety and the metal surface. As the number of molecules adsorbed on the metal surface is decreased, the molecule gets closer to the surface and the $\mathrm{C} \equiv \mathrm{N}$ moiety comes closer to the metal surface. Hence the interaction between the $\mathrm{C} \equiv \mathrm{N}$ group and metal surface increases and the intensity of the band is lowered and is absent for $1 \times 10^{-6} \mathrm{M}$. From the intensity of the bands observed for $v(\mathrm{C} \equiv \mathrm{N})$, it is possible to conclude that the interaction occurs through both the nitrogen of the aromatic ring and the nitrogen of the nitrile group even though the observation of frequencies does not suggest interaction through the nitrile nitrogen. Based on the observations, we suggest the orientation of 2cyanopyridine on gold colloid changes gradually as shown in Figure 2.7.

\subsubsection{Study of orientation of 4-biphenylcarbonitrile on gold colloid:}

The SER spectra of 4-biphenylcarbonitriles of gold colloids are shown in Figure 2.8 and the observed frequencies and band assignments are presented in Table 2.5. The molecule 4-biphenylcarbonitrile posed an interesting study because the compound has two phenyl rings and the molecule does not have a nitrogen atom in the aromatic ring. It can also be 


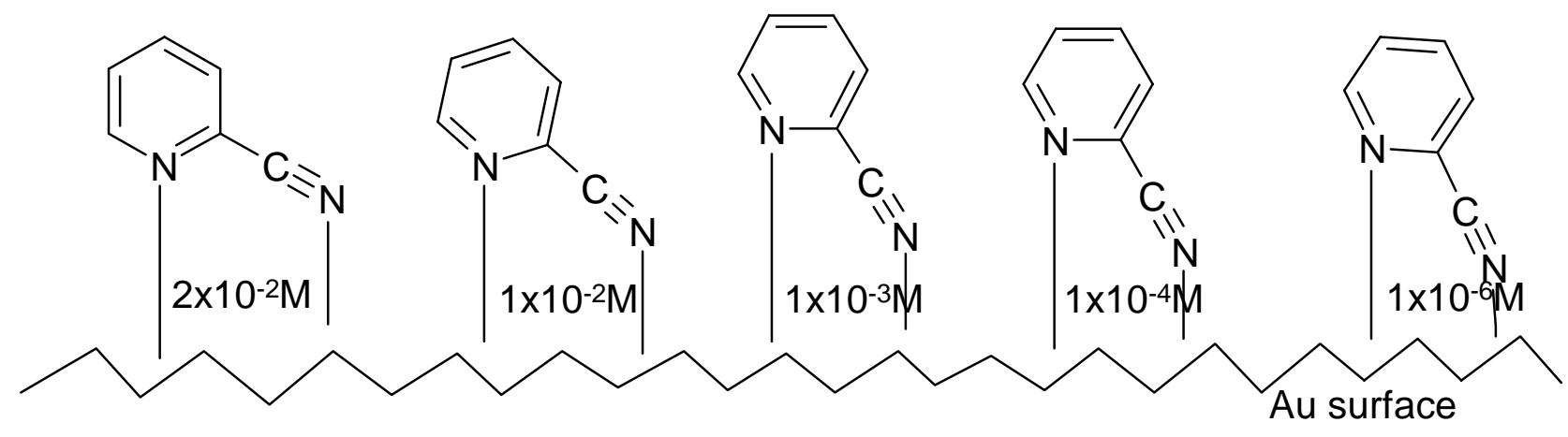

Figure 2.7 Suggested gradual change in the orientation of 2-cyanopyridine on gold colloids with change in the concentration of 2cyanopyridine 


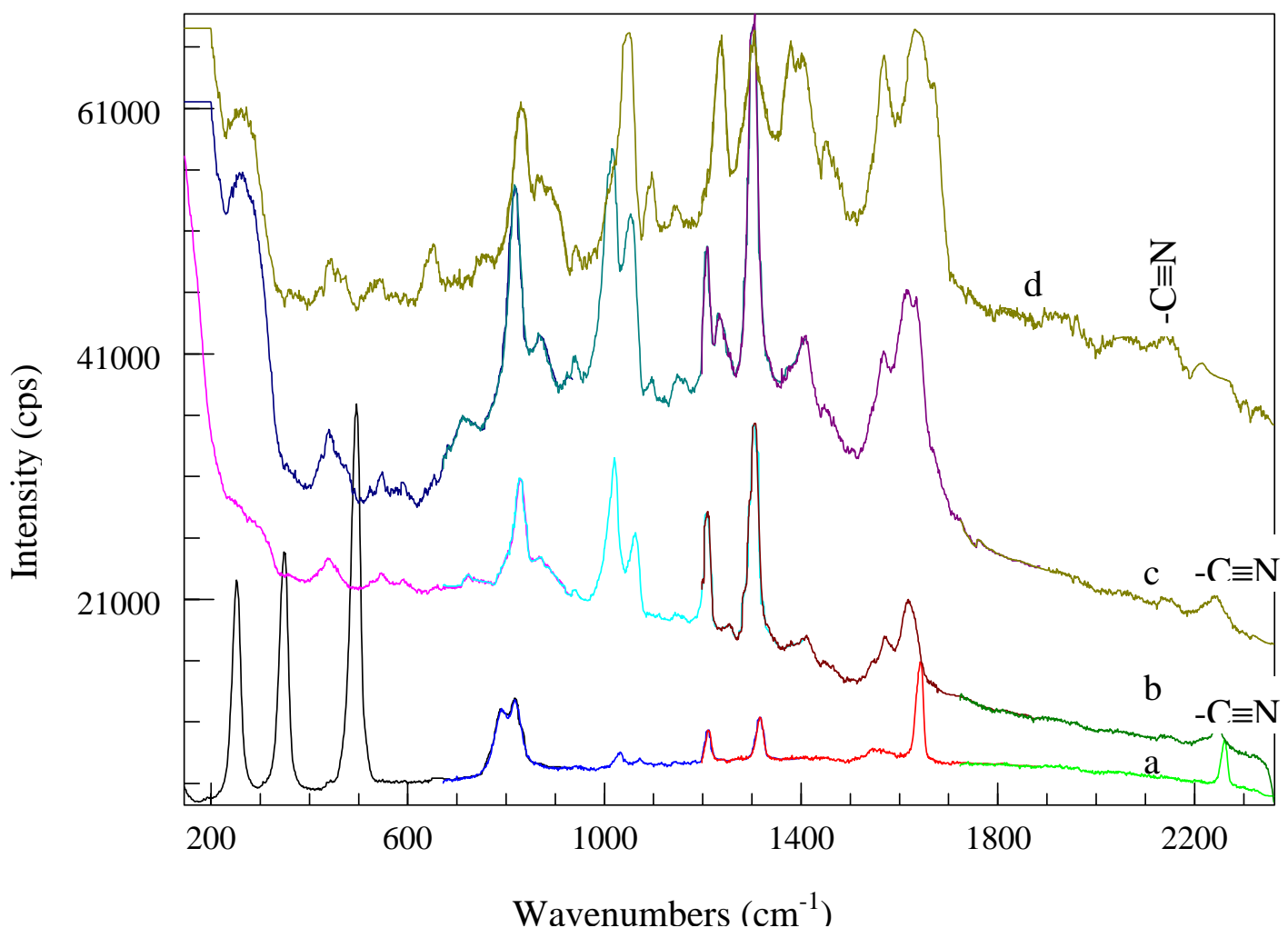

Figure 2.8 Raman spectrum of 4-biphenylcarbonitrile and SERS of 4-biphenylcarbonitrile of various concentrations adsorbed on gold colloid. (a)Parent 4-biphenylcarbonitrile in

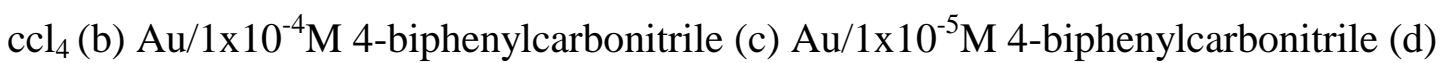
$\mathrm{Au} / 1 \times 10^{-6} \mathrm{M}$ 4-biphenylcarbonitrile 
Table 2.5 Raman frequencies of 4-biphenylcarbonitrile (4-BPN) and SERS frequencies of various concentration of 4-BPN adsorbed on gold colloid. The concentration of 4-BPN in solution ranges from $1 \times 10^{-4} \mathrm{M}$ to $1 \times 10^{-6} \mathrm{M}$.

\begin{tabular}{|l|l|l|l|l|}
\hline Band Assignment & $4 \mathrm{BPN}$ in $\mathrm{CCl}_{4}$ & $\mathrm{Au} / 10^{-4} \mathrm{M} 4 \mathrm{BPN}$ & $\mathrm{Au} / 10^{-5} \mathrm{M} 4 \mathrm{BPN}$ & $\mathrm{Au} / 10^{-6} \mathrm{M} 4 \mathrm{BPN}$ \\
\hline$\$$ & - & 442 & 442 & 428 \\
\hline$\$$ & - & - & 514 & - \\
\hline$\$(\mathrm{CCC})$ & - & 525 & 528 & 535 \\
\hline$\gamma(\mathrm{CH})$ & 648 & 657 & 642 & 642 \\
\hline$\gamma(\mathrm{CH})$ & & & & \\
\hline$\gamma(\mathrm{CH})$ & - & 820 & 814 & 814 \\
\hline Ring breathing & 994 & 857 & 857 & 857 \\
\hline$\beta(\mathrm{CH})$ & 1071 & 1042 & 942 & 942 \\
\hline$\beta(\mathrm{CH})$ & 1110 & 1114 & 980 & 994 \\
\hline
\end{tabular}




\begin{tabular}{|l|l|l|l|l|}
\hline$\beta(\mathrm{CH})$ & 1140 & 1128 & 1150 & 1128 \\
\hline$\beta(\mathrm{CH})$ & 1177 & 1142 & 1165 & - \\
\hline$\beta(\mathrm{CH})$ & 1216 & 1207 & 1214 & 1200 \\
\hline$\beta(\mathrm{CH})$ & - & 1250 & 1228 & 1277 \\
\hline$\beta(\mathrm{CH})$ & 1314 & 1300 & 1314 & 1342 \\
\hline$v(\mathrm{C}=\mathrm{C})$ & - & 1400 & 1407 & - \\
\hline$v(\mathrm{C}=\mathrm{C})$ & - & 1442 & 1442 & 1435 \\
\hline$v(\mathrm{C}=\mathrm{C})$ & 1510 & 1525 & 1525 & 1508 \\
\hline$v(\mathrm{C}=\mathrm{C})$ & 2220 & 1578 & 1578 & 1578 \\
\hline$v(\mathrm{C} \equiv \mathrm{N})$ & & 2208 & 2208 & 2166 \\
\hline
\end{tabular}


a good molecule to study steric effects due to its larger size and relative orientation of the phenyl groups. The observation of frequencies and intensities of the $\mathrm{C} \equiv \mathrm{N}$ bands can tell us about the distance of the cyano group from the surface and also which ring is attached to the metal surface, i.e. whether the ring having the $\mathrm{C} \equiv \mathrm{N}$ group is attached to the metal surface or the ring without the $\mathrm{C} \equiv \mathrm{N}$ group is attached to the metal surface.

In our studies, we adsorbed 4-biphenylcarbonitriles with a concentration range starting from $1 \times 10^{-4} \mathrm{M}$ due to the poor solubility of 4-biphenylcarbonitrile in water. The spectrum of parent 4-biphenylcarbonitrile was recorded by dissolving 4-biphenylcarbonitrile in $\mathrm{CCl}_{4}$. We chose $\mathrm{CCl}_{4}$ as the solvent because it does not interfere with the frequencies observed for the 4-biphenylcarbonitrile molecule.

The frequency of $v(C \equiv N)$ for the parent molecule occurs at $2220 \mathrm{~cm}^{-1}$. The frequency of $v(\mathrm{C} \equiv \mathrm{N})$ occurs at a lower frequency for $1 \times 10^{-4} \mathrm{M}, 1 \times 10^{-5} \mathrm{M}$ and $1 \times 10^{-6} \mathrm{M}$. The shift to lower wavenumbers is by $12 \mathrm{~cm}^{-1}$ for $1 \times 10^{-4} \mathrm{M}$ and by $18 \mathrm{~cm}^{-1}$ for $1 \times 10^{-5} \mathrm{M}$. This suggests that the orientation of the molecule at these concentrations is through the end-on configuration through the phenyl ring lacking the nitrile moiety. The shift of $v(C \equiv N)$ by $54 \mathrm{~cm}^{-1}$ for $1 \times 10^{-6} \mathrm{M}$ 4-biphenylcarbonitrile suggests that the orientation of the molecule at this concentration must be flat-on where the interaction occurs through the rings as well as the $\mathrm{C} \equiv \mathrm{N}$ bond with the metal surface. The stronger interaction of the $\mathrm{C} \equiv \mathrm{N}$ group with the metal surface, since it is in a flat-on orientation explains the very weak band observed for $\mathrm{v}(\mathrm{C} \equiv \mathrm{N})$ at this concentration.

The 4-BPN system lacks an aromatic ring nitrogen. So it poses a question as to which is the primary adsorption site for the molecule on the metal surface. From the table it can be 
seen that the ring breathing mode at $994 \mathrm{~cm}^{-1}, \beta(\mathrm{CH})$ at $1216 \mathrm{~cm}^{-1}$ and $v(\mathrm{C}=\mathrm{C})$ mode at $1606 \mathrm{~cm}^{-1}$ are shifted to lower wavenumbers for all concentrations of 4-BPN adsorbed on the metal surface. This was not observed when cyanopyridines were adsorbed on the surface of the gold colloid. The adsorption for 4-BPN should occur through the Пelectron cloud of the aromatic ring. The adsorption of the $\Pi$-electron cloud to the metal surface is much weaker than the adsorption through the lone pair of electrons of the nitrogen atom. This was found to be true since the adsorbate was allowed to stand for about 3 hours prior to recording a spectrum as compared to cyanopyridines on gold where the adsorbate was allowed to stand in the solution for only 80 minutes to record a good spectrum.

It is possible to assume that if the adsorption is end-on through the phenyl group not having the cyano group, the cyano group will be well removed from the surface. The cyano group will not experience any interaction with the metal surface and the frequency of the $\mathrm{C} \equiv \mathrm{N}$ group should remain the same as the parent molecule. In order to observe a change in the $\mathrm{C} \equiv \mathrm{N}$ frequency, the molecule should be tilted towards the metal surface. Experimentally, we observed a change in the frequency of the $\mathrm{C} \equiv \mathrm{N}$ group. The frequency was shifted by $12 \mathrm{~cm}^{-1}$ for $1 \times 10^{-4} \mathrm{M}$ and by $18 \mathrm{~cm}^{-1}$ for $1 \times 10^{-5} \mathrm{M}$ and by $54 \mathrm{~cm}^{-1}$ for the $1 \times 10^{-6} \mathrm{M}$ concentration. This suggests that for $1 \times 10^{-4} \mathrm{M}$ and $1 \times 10^{-5} \mathrm{M}$, the molecule should lie tilted towards the metal surface so as to bring the cyano group closer to the metal and the interaction through the $\prod$-electron cloud of the aromatic ring retaining the end-on orientation. At $1 \times 10^{-6} \mathrm{M}$, the molecule lies flat on since the shift is by $54 \mathrm{~cm}^{-1}$. Based on these observations, the orientation of 4-biphenylcarbonitrile on the gold colloid can be suggested as shown in Figure 2.9. 


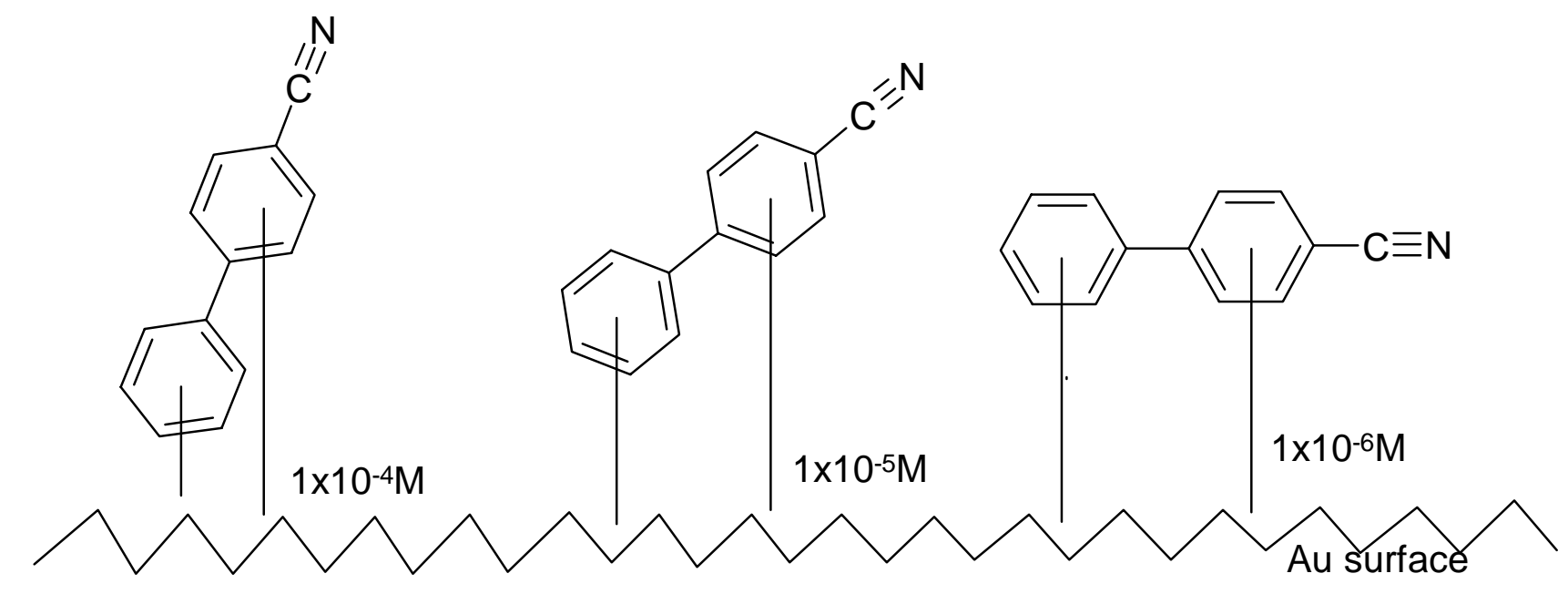

Figure 2.9 Suggested gradual change in the orientation of 4-biphenylcarbonitrile on gold colloid with change in concentration of 4biphenylcarbonitrile 


\subsubsection{Study of orientation of aminomethylpyridines on copper colloid:}

\section{4-aminomethyl pyridine on copper colloids:}

Previously in our laboratory it was found that when cyanopyridines were adsorbed on copper colloids, the $\mathrm{C} \equiv \mathrm{N}$ group was reduced to an aminomethyl group ${ }^{17}$ It was proposed that the borohydride used during the preparation of copper colloid reduces the cyano group to the aminomethyl group. Thus the spectrum which was recorded when cyanopyridine was adsorbed on the copper colloid was indeed aminomethylpyridine adsorbed on copper colloid. ${ }^{17}$

We recorded the spectra of 4-aminomethyl pyridine adsorbed on copper colloid for concentration of 4 -aminomethyl pyridine ranging from $1.7 \times 10^{-2} \mathrm{M}$ to $8.7 \times 10^{-7} \mathrm{M}$. The SER spectra of 4-aminomethylpyridines adsorbed on copper colloid are shown in Figure 2.10 and the tentative band assignments are shown in Table 2.6. The shift of ring breathing mode occurring around $1000 \mathrm{~cm}^{-1}$, the $\beta(\mathrm{CH})$ mode occurring around $1200 \mathrm{~cm}^{-1}$ and the $v(\mathrm{C}=\mathrm{C})$ mode occurring around $1600 \mathrm{~cm}^{-1}$ towards lower values would indicate the orientation to be end-on and the shift of these bands towards higher wavenumbers would indicate the orientation to be flat on. From the table it can be seen that the ring breathing mode occurring at $994 \mathrm{~cm}^{-1}$, the $\beta(\mathrm{CH})$ occurring at $1196 \mathrm{~cm}^{-1}$ and the $v(\mathrm{C}=\mathrm{C})$ occurring at $1575 \mathrm{~cm}^{-1}$ are shifted towards higher wavenumbers for all concentrations of the molecules 4-aminomethylpyridines ranging from $1.7 \times 10^{-2} \mathrm{M}$ to $8.7 \times 10^{-6} \mathrm{M}$ and shifts to lower wavenumbers for $8.7 \times 10^{-7} \mathrm{M}$ concentration of 4-aminomethylpyridine. Therefore we assume that the orientation is flat-on for concentrations ranging from $1.7 \times 10^{-2} \mathrm{M}$ to $8.7 \times 10^{-6} \mathrm{M}$ and the orientation is end-on for $8.7 \times 10^{-7} \mathrm{M}$ concentration. 


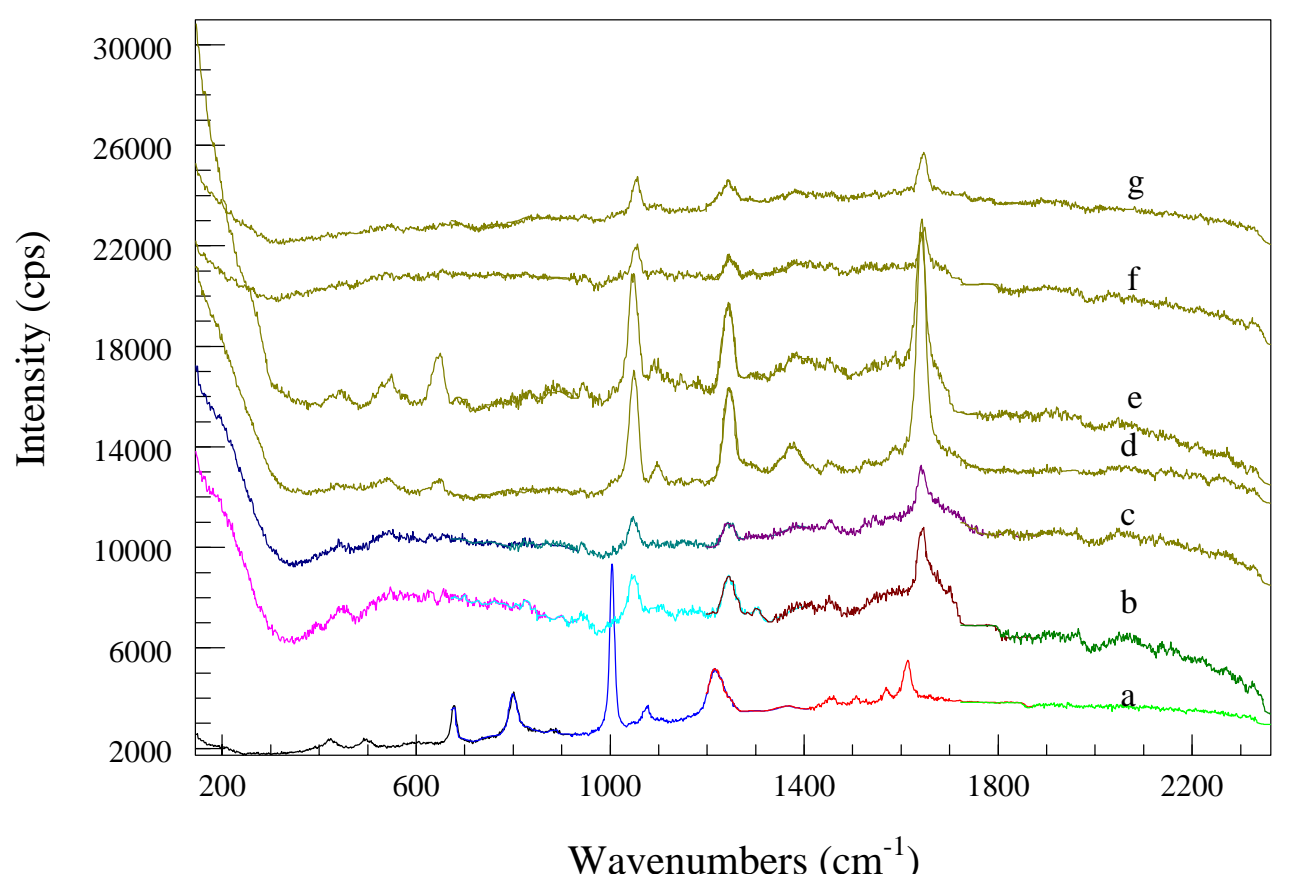

Figure 2.10 Raman spectrum of 4-aminomethylpyridine and SERS of 4aminomethylpyridines of various concentrations adsorbed on copper colloids.(a)Parent 4-aminomethylpyridine (b) $\mathrm{Cu} / 1.7 \times 10^{-2} \mathrm{M}$ 4-aminomethylpyridine (c) $\mathrm{Cu} / 8.7 \times 10^{-3} \mathrm{M} 4$ aminomethylpyridine(d) $\mathrm{Cu} / 8.7 \times 10^{-4} \mathrm{M}$ 4-aminomethylpyridine (e) $\mathrm{Cu} / 8.7 \times 10^{-5} \mathrm{M} 4-$ aminomethylpyridine (f) $\mathrm{Cu} / 8.7 \times 10^{-6} \mathrm{M}$ 4-aminomethylpyridine $(\mathrm{g}) \mathrm{Cu} / 8.7 \times 10^{-7} \mathrm{M} 4$ aminomethylpyridine 
Table 2.6 Raman frequencies of neat 4-aminomethylpyridine (4-AMP) and SERS frequencies of various concentrations of 4-aminomethylpyridine adsorbed on copper colloids. The concentration of 4-aminomethylpyridine in solution ranges from $1.7 \times 10^{-2} \mathrm{M}$ to $8.7 \times 10^{-7} \mathrm{M}$

\begin{tabular}{|c|c|c|c|c|c|c|c|}
\hline $\begin{array}{l}\text { Band } \\
\text { Assignment }\end{array}$ & $\begin{array}{l}\text { Neat } \\
\text { 4AMP } \\
\text { liquid }\end{array}$ & $\begin{array}{l}\mathrm{Cu} / 1.7 \times 10^{-} \\
{ }^{2} \mathrm{M} 4 \mathrm{AMP}\end{array}$ & $\begin{array}{l}\mathrm{Cu} / 8.7 \times 10^{-} \\
{ }^{3} \mathrm{M} 4 \mathrm{AMP}\end{array}$ & $\begin{array}{l}\mathrm{Cu} / 8.710^{-} \\
{ }^{4} \mathrm{M} \\
4 \mathrm{AMP}\end{array}$ & $\begin{array}{l}\mathrm{Cu} / 8.7 \times 10^{-} \\
{ }^{5} \mathrm{M} 4 \mathrm{AMP}\end{array}$ & $\begin{array}{l}\mathrm{Cu} / 8.7 \times 10^{-} \\
{ }^{6} \mathrm{M} 4 \mathrm{AMP}\end{array}$ & $\begin{array}{l}\mathrm{Cu} / 8.7 \times 10^{-} \\
{ }^{7} \mathrm{M} 4 \mathrm{AMP}\end{array}$ \\
\hline$\$$ & 431 & 442 & 428 & 414 & 428 & 443 & - \\
\hline $\begin{array}{l}\text { Ring } \\
\text { deformation }\end{array}$ & 506 & 542 & 535 & 528 & 528 & 514 & 514 \\
\hline $\mathrm{Y}\left(\mathrm{NH}_{2}\right)$ & 612 & 614 & - & 628 & 628 & 621 & 621 \\
\hline$\$$ & 687 & 642 & 664 & - & - & - & - \\
\hline$\gamma(\mathrm{CH})$ & 756 & 742 & 735 & - & - & 728 & - \\
\hline$v(C=C)$ & 818 & 799 & 814 & - & - & 814 & - \\
\hline$\beta(\mathrm{CH})$ & 900 & 928 & - & - & 914 & - & 899 \\
\hline $\begin{array}{l}\text { Ring } \\
\text { breathing }\end{array}$ & 994 & 1013 & 1014 & 1014 & 1014 & 1014 & 985 \\
\hline
\end{tabular}




\begin{tabular}{|c|c|c|c|c|c|c|c|}
\hline $\begin{array}{l}\beta\left(\mathrm{NH}_{2}\right), \\
\beta(\mathrm{CH})\end{array}$ & 1093 & 1056 & 1049 & 1057 & 1057 & 1057 & 1028 \\
\hline$\beta(\mathrm{CH})$ & 1196 & 1199 & 1192 & 1214 & 1200 & 1185 & 1171 \\
\hline$\$$ & 1381 & 1342 & 1356 & 1328 & 1328 & 1314 & 1299 \\
\hline$v(C=C)$ & 1475 & - & 1414 & 1485 & 1414 & - & - \\
\hline$v(C=C)$ & 1531 & - & - & - & - & - & - \\
\hline$v(C=C)$ & 1593 & - & - & 1535 & 1528 & - & - \\
\hline$v(C=C)$ & 1575 & 1599 & 1585 & 1606 & 1585 & 1585 & 1542 \\
\hline
\end{tabular}


The spectra for various concentrations of 4AMP on copper colloid show intense bands for the ring breathing mode, $\beta(\mathrm{CH})$ at around $1200 \mathrm{~cm}^{-1}$ and $v(\mathrm{C}=\mathrm{C})$ at around $1600 \mathrm{~cm}^{-1}$. There is not considerable difference in the intensity from these bands at various concentrations of 4AMPs though the most intense spectrum is obtained when $8.7 \times 10^{-4} \mathrm{M}$ concentration of 4AMP is adsorbed on the copper colloid.

\section{3 aminomethylpyridine on copper colloids}

3-aminomethylpyridine was adsorbed on copper colloids for concentrations ranging from $1.7 \times 10^{-2} \mathrm{M}$ to $8.7 \times 10^{-7} \mathrm{M}$ concentrations. The spectra for the various concentrations of aminomethylpyridines adsorbed on copper colloid are shown in Figure 2.11 and the tentative band assignments are shown in Table 2.7.

The observation of ring breathing mode, $\beta(\mathrm{CH})$ mode and $v(\mathrm{C}=\mathrm{C})$ mode helps us to predict the change in orientation of aminomethylpyridines on copper colloids. The ring breathing mode occurs at $1014 \mathrm{~cm}^{-1}, \beta(\mathrm{CH})$ occurs at $1040 \mathrm{~cm}^{-1}$ and $v(\mathrm{C}=\mathrm{C})$ occurs at $1571 \mathrm{~cm}^{-1}$ for the free 3 -aminomethylpyridine molecule. These vibrational modes are shifted to higher wavenumbers for concentrations of 3-aminomethylpyridines ranging from $1.7 \times 10^{-2} \mathrm{M}$ to $8.7 \times 10^{-6} \mathrm{M}$ and are shifted to a lower wavenumber for $8.7 \times 10^{-7} \mathrm{M}$ concentration. Again, from these observations it is possible to assume that the orientation is flat-on for concentrations of 3 -aminomethylpyridines ranging from $1.7 \times 10^{-2} \mathrm{M}$ to $8.7 \times 10^{-6} \mathrm{M}$ and is end-on for concentration at $8.7 \times 10^{-7} \mathrm{M}$. 


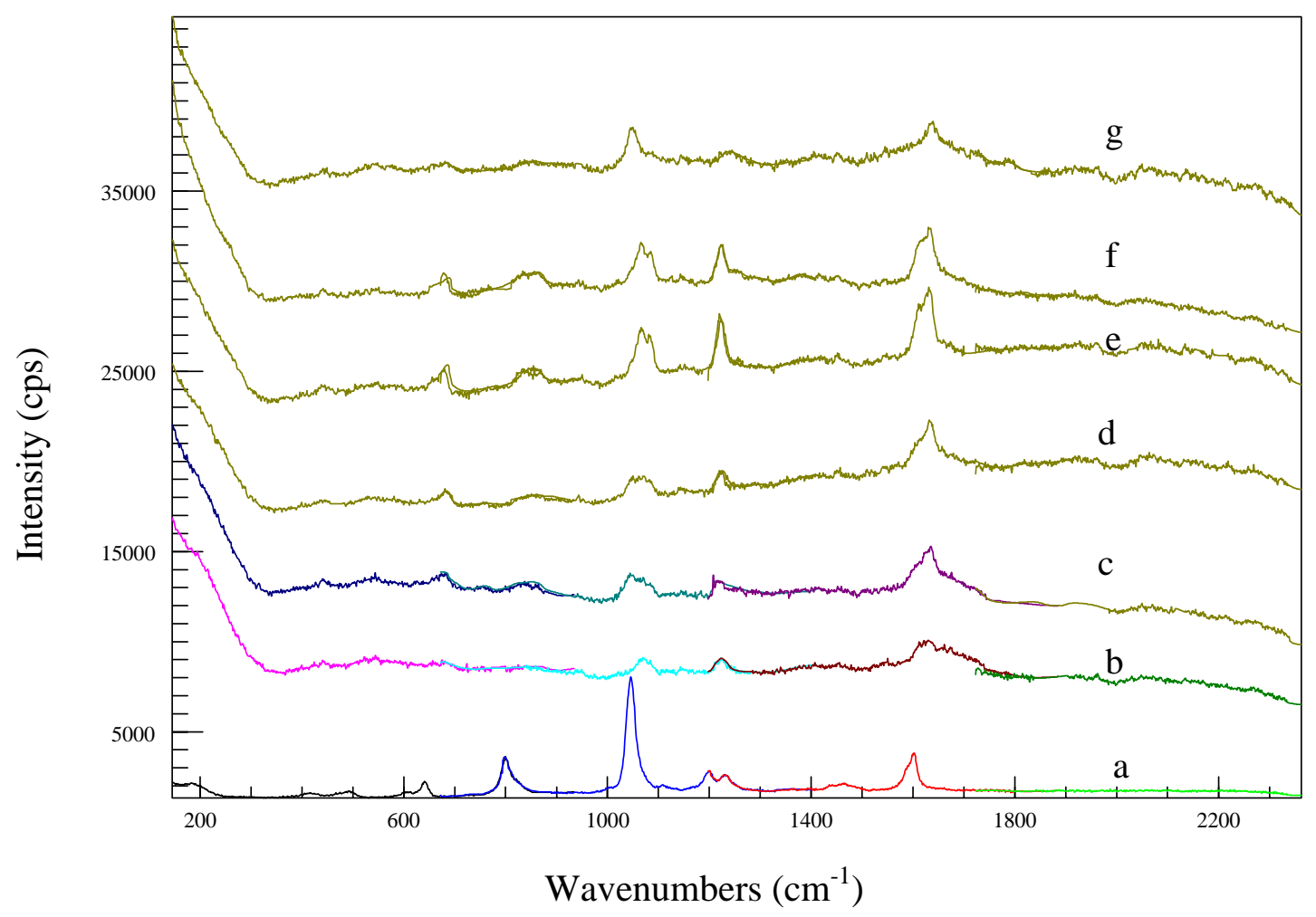

Figure 2.11 Raman spectrum of 3-aminomethylpyridine and SERS of 3aminomethylpyridines of various concentration adsorbed on copper colloids. (a) Parent 3aminomethylpyridine (b) $\mathrm{Cu} / 1.7 \times 10^{-2} \mathrm{M} 3$-aminomethylpyridine (c) $\mathrm{Cu} / 8.7 \times 10^{-3} \mathrm{M} 3$ aminomethylpyridine (d) $\mathrm{Cu} / 8.7 \times 10^{-4} \mathrm{M} 3$-aminomethylpyridine (e) $\mathrm{Cu} / 8.7 \times 10^{-5} \mathrm{M} 3$ aminomethylpyridine (f) $\mathrm{Cu} / 8.7 \times 10^{-6} \mathrm{M}$ 3-aminomethylpyridine (g) $\mathrm{Cu} / 8.7 \times 10^{-7} \mathrm{M} 3$ aminomethylpyridine 
Table 2.7 Raman frequencies of neat 3-aminomethylpyridine (3-AMP) and SERS frequencies of various concentrations of 3aminomethylpyridine adsorbed on copper colloids. The concentration of 3-AMP in solution ranges from $1.7 \times 10^{-2} \mathrm{M}$ to $8.7 \times 10^{-7} \mathrm{M}$

\begin{tabular}{|c|c|c|c|c|c|c|c|}
\hline $\begin{array}{l}\text { Band } \\
\text { Assignment }\end{array}$ & $\begin{array}{l}\text { Neat 3AMP } \\
\text { liquid }\end{array}$ & $\begin{array}{l}\mathrm{Cu} / 1.7 \times 10^{-2} \mathrm{M} \\
3 \mathrm{AMP}\end{array}$ & $\begin{array}{l}\mathrm{Cu} / 8.7 \times 10^{-3} \mathrm{M} \\
3 \mathrm{AMP}\end{array}$ & $\begin{array}{l}\mathrm{Cu} / 8.7 \times 10^{-4} \mathrm{M} \\
3 \mathrm{AMP}\end{array}$ & $\begin{array}{l}\mathrm{Cu} / 8.7 \times 10^{-5} \mathrm{M} \\
3 \mathrm{AMP}\end{array}$ & $\begin{array}{l}\mathrm{Cu} / 8.7 \times 10^{-6} \mathrm{M} \\
3 \mathrm{AMP}\end{array}$ & $\begin{array}{l}\mathrm{Cu} / 8.7 \times 10^{-7} \mathrm{M} \\
3 \mathrm{AMP}\end{array}$ \\
\hline$\$$ & 185 & - & - & - & - & - & - \\
\hline $\begin{array}{l}\text { Ring } \\
\text { deformation }\end{array}$ & 399 & 428 & 428 & 428 & 428 & 428 & 428 \\
\hline$\gamma\left(\mathrm{NH}_{2}\right)$ & 471 & 528 & 543 & 514 & 528 & 528 & 528 \\
\hline$\$$ & 585 & - & - & - & - & - & - \\
\hline$\alpha(\mathrm{CCC})$ & 614 & 671 & 664 & 657 & 657 & 664 & 657 \\
\hline$v(C=C)$ & 771 & - & 742 & 771 & - & - & 799 \\
\hline$\alpha(\mathrm{CCC})$ & 978 & - & - & - & - & - & - \\
\hline $\begin{array}{l}\text { Ring } \\
\text { breathing }\end{array}$ & 1014 & 1031 & 1020 & 1028 & 1028 & 1028 & 1006 \\
\hline
\end{tabular}




\begin{tabular}{|c|c|c|c|c|c|c|c|}
\hline $\begin{array}{l}\beta\left(\mathrm{NH}_{2}\right), \\
\beta(\mathrm{CH})\end{array}$ & 1038 & 1049 & 1042 & 1042 & 1042 & 1042 & 1030 \\
\hline$\beta\left(\mathrm{NH}_{2}\right), \beta(\mathrm{CH})$ & 1171 & - & 1106 & 1114 & - & - & 1114 \\
\hline $\begin{array}{l}\beta\left(\mathrm{NH}_{2}\right), \\
\beta(\mathrm{CH})\end{array}$ & & 1185 & & & 1185 & 1185 & 1199 \\
\hline$v(C=C)$ & 1328 & 1364 & 1371 & - & - & 1371 & - \\
\hline$v(C=C)$ & 1363 & 1407 & 1414 & 1414 & 1406 & 1414 & - \\
\hline$v(C=C)$ & 1399 & 1499 & - & 1492 & 1499 & - & - \\
\hline$v(C=C)$ & 1428 & - & - & - & - & - & - \\
\hline$v(C=C)$ & 1571 & 1585 & 1585 & 1585 & 1585 & 1585 & 1585 \\
\hline
\end{tabular}


2-aminomethylpyridines on copper colloids

2-Aminomethylpyridine was adsorbed on copper colloid for concentrations ranging from $1.7 \times 10^{-2} \mathrm{M}$ to $8.7 \times 10^{-7} \mathrm{M}$. The spectra of 2-aminomethylpyridines adsorbed on copper colloids for various concentrations are shown in Figure 2.12 and the tentative band assignments are shown in Table 2.8.

Again, the observation of the ring breathing mode, the $\beta(\mathrm{CH})$ mode and the $v(\mathrm{C}=\mathrm{C})$ modes will help to predict the orientation changes with changes in the concentration of the adsorbates. The ring breathing mode occurs at $1014 \mathrm{~cm}^{-1}$, the $\beta(\mathrm{CH})$ mode occurs at $1228 \mathrm{~cm}^{-1}$ and the $v(\mathrm{C}=\mathrm{C})$ mode occurs at $1557 \mathrm{~cm}^{-1}$ and $1585 \mathrm{~cm}^{-1}$. The observation of frequencies for these modes for 2-aminomethylpridine predicts a different trend as compared with 4-aminomethylpyridine and 3-aminomethylpyridine. The frequency shift for these modes is towards a higher wavenumber for $1.7 \times 10^{-2} \mathrm{M}$ and towards lower wavenumbers for concentrations of 2-aminomethylpyridines ranging from $8.7 \times 10^{-3} \mathrm{M}$ to $8.7 \times 10^{-7} \mathrm{M}$. This helps to assume that the orientation of 2-aminomethylpyridine is flat on at $1.7 \times 10^{-2} \mathrm{M}$ concentration and is end-on at concentrations ranging from $8.7 \times 10^{-3} \mathrm{M}$ to $8.7 \times 10^{-7} \mathrm{M}$. 


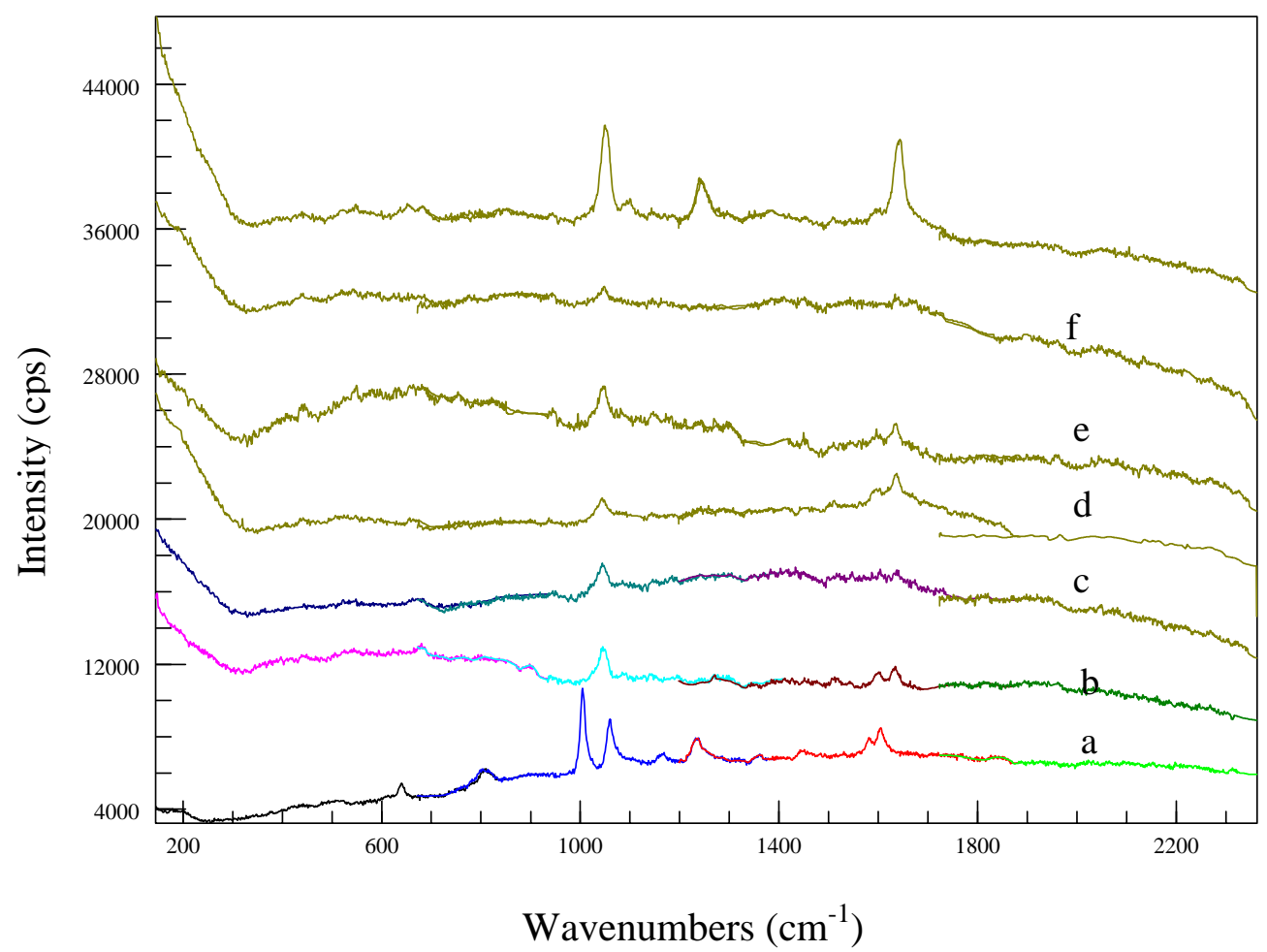

Figure 2.12 Raman spectrum of 2-aminomethylpyridine and SERS of 2aminomethylpyridine adsorbed on copper colloids. (a) parent 2-aminomethylpyridine (b) $\mathrm{Cu} / 1.7 \times 10^{-2} \mathrm{M}$ 2-aminomethylpyridine (c) $\mathrm{Cu} / 8.7 \times 10^{-3} \mathrm{M}$ 2-aminomethylpyridine (d) $\mathrm{Cu} / 8.7 \times 10^{-4} \mathrm{M}$ 2-aminomethylpyridine (e) $\mathrm{Cu} / 8.7 \times 10^{-5} \mathrm{M}$ 2-aminomethylpyridine (f) $\mathrm{Cu} / 8.7 \times 10^{-6} \mathrm{M} 2$-aminomethylpyridine (g) $\mathrm{Cu} / 8.7 \times 10^{-7} \mathrm{M}$ 2-aminomethylpyridine 
Table 2.8 Raman frequencies of neat 2-aminomethylpyridine (2-AMP) and SERS frequencies of various concentrations of 2aminomethylpyridine adsorbed on copper colloids. The concentration of 2 -aminomethylpyridine in solution ranges from $1.7 \times 10^{-2} \mathrm{M}$ to $8.7 \times 10^{-7} \mathrm{M}$.

\begin{tabular}{|c|c|c|c|c|c|c|c|}
\hline $\begin{array}{l}\text { Band } \\
\text { Assignment }\end{array}$ & $\begin{array}{l}\text { Neat } \\
2 \mathrm{AMP}\end{array}$ & $\begin{array}{l}\mathrm{Cu} / 1.7 \times 10^{-2} \mathrm{M} \\
2 \mathrm{AMP}\end{array}$ & $\begin{array}{l}\mathrm{Cu} / 8.7 \times 10^{-3} \mathrm{M} \\
2 \mathrm{AMP}\end{array}$ & $\begin{array}{l}\mathrm{Cu} / 8.710^{-4} \mathrm{M} \\
2 \mathrm{AMP}\end{array}$ & $\begin{array}{l}\mathrm{Cu} / 8.7 \times 10^{-5} \mathrm{M} \\
2 \mathrm{AMP}\end{array}$ & $\begin{array}{l}\mathrm{Cu} / 8.7 \times 10^{-6} \mathrm{M} \\
2 \mathrm{AMP}\end{array}$ & $\begin{array}{l}\mathrm{Cu} / 8.7 \times 10^{-7} \mathrm{M} \\
2 \mathrm{AMP}\end{array}$ \\
\hline $\begin{array}{l}\mathrm{C}=\mathrm{N} \text { sensitive, } \\
\delta(\mathrm{CN})\end{array}$ & & 185 & & & & & \\
\hline $\begin{array}{l}\phi(\mathrm{CC}), \mathrm{C}=\mathrm{N} \text { sens, } \\
\delta(\mathrm{CN})\end{array}$ & 428 & 428 & 407 & 421 & 414 & 428 & 428 \\
\hline $\mathrm{C}=\mathrm{N}$ sens, $\delta(\mathrm{CN})$ & 457 & - & 442 & 485 & - & 499 & \\
\hline $\mathrm{C}=\mathrm{N}$ sens,$\delta(\mathrm{CN})$ & 507 & 521 & 514 & - & 528 & 528 & 564 \\
\hline$\$$ & 521 & 535 & 543 & - & - & - & \\
\hline$\alpha(\mathrm{CCC})$ & 643 & 657 & 657 & 657 & 657 & 657 & 642 \\
\hline $\mathrm{C}=\mathrm{N}$ sens & 799 & 785 & - & 799 & 792 & - & - \\
\hline
\end{tabular}




\begin{tabular}{|c|c|c|c|c|c|c|c|}
\hline$\$$ & & 871 & 835 & & & & \\
\hline$\$$ & & & 914 & & & & \\
\hline Ring breathing & 1014 & 1021 & 1006 & 1006 & 1006 & 1006 & 1028 \\
\hline$\beta(\mathrm{CH})$ & 1057 & 1071 & 1042 & - & 1042 & - & 1057 \\
\hline$\beta(\mathrm{CH})$ & 1114 & 1121 & 1114 & 1114 & 1142 & - & 1135 \\
\hline$\beta(\mathrm{CH})$ & 1142 & 1171 & 1149 & 1149 & 1199 & - & 1149 \\
\hline$\beta(\mathrm{CH})$ & 1228 & 1242 & 1228 & 1200 & 1200 & 1213 & 1214 \\
\hline $\mathrm{C}=\mathrm{N}$ sens & & & 1328 & 1328 & 1371 & 1371 & - \\
\hline$\$$ & 1399 & - & 1399 & 1399 & 1399 & 1399 & - \\
\hline
\end{tabular}




\begin{tabular}{|c|c|c|c|c|c|c|c|}
\hline$v(\mathrm{C}=\mathrm{C}), v(\mathrm{CN})$ & - & 1463 & 1463 & 1456 & 1456 & 1485 & 1463 \\
\hline$v(\mathrm{C}=\mathrm{C}), \mathrm{v}(\mathrm{CN})$ & & 1492 & - & - & - & - & - \\
\hline$v(C=C)$ & 1557 & 1563 & 1556 & 1549 & 1542 & 1556 & 1549 \\
\hline$v(C=C)$ & 1585 & 1585 & 1585 & 1585 & 1587 & 1585 & 1585 \\
\hline
\end{tabular}




\section{Summary}

The orientation of 4-cyanopyridine, 3-cyanopyridine and 2-cyanopyridine, 4biphenylcarbonitrile on gold colloids and orientation of 4-aminomethylpyridine, 3aminomethylpyridine and 2-aminomethylpyridine on copper colloids were studied. The concentration of the adsorbates added to the colloids ranged from $2 \times 10^{-2} \mathrm{M}$ to $1 \times 10^{-6} \mathrm{M}$ for cyanopyridines and $1.7 \times 10^{-2} \mathrm{M}$ to $8.7 \times 10^{-7} \mathrm{M}$ for aminomethylpyridines and ranged from $1 \times 10^{-4} \mathrm{M}$ to $1 \times 10^{-6} \mathrm{M}$ for 4-biphenylcarbonitriles. It was found that the orientation is end-on for all concentrations of cyanopyridines (4-, 3- and 2-) adsorbed on gold colloids with the primary interaction being through the aromatic nitrogen. It was found that for 4biphenylcarbonitrile the orientation was approaching flat on for $1 \times 10^{-4} \mathrm{M}$ and $1 \times 10^{-5} \mathrm{M}$ concentrations and is in a flat-on orientation for $1 \times 10^{-6} \mathrm{M}$ concentration. It was assumed that the interaction was through the $\prod$-electron cloud of the aromatic ring and the molecule was oriented such that it lies tilted towards the metal surface. The change in the frequency value for the nitrile group upon adsorption allowed us to infer that the orientation of the molecule is not perfect end-on. It was found that the orientation of aminomethylpyridines changed when adsorbed on the copper colloids. The orientation was flat-on for 4-aminomethylpyridine and 3-aminomethylpyridine for concentrations ranging from $1.7 \times 10^{-2} \mathrm{M}$ to $8.7 \times 10^{-6} \mathrm{M}$ and was end-on $8.7 \times 10^{-7} \mathrm{M}$ concentration. The orientation for 2-aminomethylpyridine on copper colloid was end-on $1.7 \times 10^{-2} \mathrm{M}$ concentration and was flat-on for concentrations ranging from $8.7 \times 10^{-3} \mathrm{M}$ to $8.7 \times 10^{-7} \mathrm{M}$. So it can be concluded that for concentrations $8.7 \times 10^{-3} \mathrm{M}$ to $8.7 \times 10^{-6} \mathrm{M}$, the orientation is flat on for 4-, 3- and 2-aminomethylpyridines and the orientation changes only for the $1.7 \times 10^{-2} \mathrm{M}$ and $8.7 \times 10^{-7} \mathrm{M}$ concentrations. 
It is reasonable to assume that the nature of the metal colloid is important in deciding the orientation changes of the adsorbates. The gold colloid does not change the orientation of the adsorbates but the copper colloid changes the orientation of the adsorbates. 


\section{References}

1. C. S. Allen, PhD Thesis, NorthWestern University (1980); University Microfilms, AAG8104683.

2. H. Metiu, R. P. Das, Annual Review of Physical Chemistry, 35, 507, 1984.

3. C. S. Allen, G. C. Schatz, R. P. Van Duyne, Chemical Physics Letters, 75, 201, 1980.

4. J. A. Creighton, Analytical Proceedings, 30, 28, 1993.

5. M. Kerker, D. S. Wang, H. Chew, Applied Optics, 19, 4159, 1980.

6. D. S. Wang, H. Chew, M. Kerker, Applied Optics, 19, 2256, 1980.

7. J. C. Rubim, O. Sala, Journal of Molecular Spectroscopy, 145, 157, 1986.

8. G. T. Merklin, P. R. Griffiths, Journal of Physical Chemistry B, 101, 5810, 1997.

9. J. C. Rubim, Journal of Electroanalytical Chemistry, 220, 339, 1987.

10. M. Fleischmann, P. J. Hendra, A. J. McQuillan, Chemical Physics Letters, 26, 163, 1974.

11. C. S. Allen, R. P. Van Duyne, Journal of American Chemical Society, 103, 7497, 1981.

12. D. Meisel, P. C. Lee, Journal of Physical Chemistry, 86, 3391, 1982.

13. J. C. Creighton, D. G. Eadon, Journal of Chemical Society, Faraday Transactions, 2487, 3881, 1991. 
14. J. A. Creighton, M. S. Alvarez, D. A. Weltz, S. Garaff, M. W. Kim, Journal of Physical Chemistry, 87, 4793, 1983.

15. J. C. Rubim, Journal of Electroanalytical Chemistry, 220, 339, 1987.

16. J. C. Rubim, O. J. Sala, Journal of Molecular Structure, 145, 157, 1986.

17. C. M. Coyle, G. Chumanov, P. W. Jagodzinski, Journal of Raman Spectroscopy, 29, 757, 1998. 


\section{CHAPTER 3}

\section{MOLECULAR MODELING STUDIES OF SURFACE-ADSORBATE INTERACTIONS}

\subsection{Introduction}

We have attempted to model the metal surface-adsorbates using SpartanPro 1.0. ${ }^{1}$ software and have performed calculations using the Molecular Mechanics Force Field (MMFF) method. Our modeling of the metal-adsorbate system gave values for the frequencies of the vibrations that were close to the experimental values. We present herein the models of the systems and the frequencies obtained for the various vibrations and the models and compare them with the experimental values.

In the classical approach, a vibrating molecule is modeled successfully as balls attached to the end of the springs. The first mention of this technique is described in the literature paper by Andrews. ${ }^{2}$ The first practical calculation was performed by Westheimer and Meyer. ${ }^{3}$ The simplest possible equation to describe a vibrational motion is the simple harmonic oscillator model. It gives the classical vibration frequency of the system as

$v=1 / 2 \Pi \sqrt{ } \mathrm{k}_{\mathrm{s}} / \mathrm{m}$

Where $\mathrm{k}_{\mathrm{s}}$ is the force constant of the spring and $\mathrm{m}$ is the mass.

The wavenumbers in terms of energies which is referred to as classical vibrational wavenumber, $\omega_{\mathrm{e}}$, is given as 
$\omega_{\mathrm{e}}=1 / 2 \Pi \operatorname{Co} \sqrt{\mathrm{s}}_{\mathrm{s}} / \mathrm{m}$

Where $\mathrm{k}_{\mathrm{s}}$ is the force constant of the spring and $\mathrm{m}$ is the mass.

The analysis of the vibrational spectrum gives the force constant $\mathrm{k}_{\mathrm{s}}$. However a real molecule does not vibrate as if it were simple particles at the ends of classical springs. In the quantum mechanical treatment, the potential of the system is written in terms of the Morse function. The second derivativee of the potential gives the value for the force constant and thereby the vibrational frequency is calculated using the classical treatment. ${ }^{4}$

The aim of Molecular Mechanics is to predict the molecular geometry by minimizing the intramolecular potential energy. ${ }^{4}$ The first derivative of the potential gives the equilibrium geometry and the second derivative of the potential gives the value for the force constant. This model is invariably used for the calculation of the most energetically favorable geometry.

\subsection{Calculations}

The modeling of the systems was done using the Spartan Pro 1.0 version. The model was constructed by joining three metal atoms. Each organonitrile was then placed over the metal surface. The dihedral angle between the metal and the organonitriles was constrained to zero degree. This allowed both the moieties to be in the same plane of the surface. The organonitrile was oriented such that either the aromatic nitrogen or nitrile nitrogen was pointing towards the surface. The limitation of this model is the metal surface is represented only by three metal atoms and only one organonitrile molecule is adsorbed on it. The coupling effect of many metal atoms and organonitriles has not been considered. 
The calculations were performed using the Molecular Mechanics Force Field (MMFF) method. The model consists of a metal surface and an organonitrile adsorbed over it. The two moieties are not joined by a bond but are placed close to each other so that there is interaction between the two species. The symmetries do not converge while using methods such as Hartree-Fork, semi-empirical method and density functional method and hence it is not possible to obtain the vibrational frequencies with these methods. While in the case of Molecular Mechanics Force Field Method, it minimizes the energy with the modeled structure and it was possible to get the vibrational frequencies with this method. The vibrational frequencies obtained were compared with the experimental data to verify if the models were good enough to mimic the metal-adsorbate system. The angles, dihedral angle and the distances between the metal surface and the adsorbate were adjusted until a geometry was reached which agreed well with the experimental values. This geometry was then compared with the orientation consistent with the experimentally observed SERS frequencies.

\subsection{Results And Discussion}

\subsubsection{4-cyanopyridines on gold colloids:}

The comparisons between the experimental values and calculated values for some of the important vibrational assignments are presented in Table 3.1. Comparisons are also made for the three possible orientations [flat on, end-on (interaction through nitrogen of the aromatic ring and interaction through the nitrogen of the cyanide group] of cyanopyridines on gold colloids. From the table, we can assume that the model is a good representation of the real system as it is in close agreement with the experimental value. 
From the table it is possible to conclude that the orientation for the 4-cyanopyridine on gold is through the nitrogen atom of the aromatic ring. The best results were obtained when the distance between the nitrogen atom of the aromatic ring and the gold surface was constrained as 0.1 angstrom units.

The end-on alignment should shift the frequency values of ring breathing, $\beta(\mathrm{CH}), v(\mathrm{C}=\mathrm{C})$ to higher wavenumbers with respect to the free molecule and should shift the frequency value of $v(C \equiv N)$ to lower wavenumbers. The shift of the frequency values for ring breathing, $\beta(\mathrm{CH}), \mathrm{v}(\mathrm{C}=\mathrm{C})$ should be to lower wavenumbers for flat-on and the shift the frequency value of $v(\mathrm{C} \equiv \mathrm{N})$ should be further down to lower wavenumbers as compared for end-on alignment. If the interaction to the metal surface is through the nitrogen of the nitrile group, then the value of $v(\mathrm{C} \equiv \mathrm{N})$ should be shifted upwards as compared to the free molecule. By comparing the values in the table for various orientations and the experimental values, it can be concluded that the orientation is end-on through the nitrogen atom of the aromatic ring.

From the model and the calculations, it is reasonable to propose that the orientation of the 4-cyanopyridine molecule on the gold surface is end-on through the nitrogen atom and the distance between the 4-cyanopyridine and gold surface is approximately $0.1 \mathrm{~A}^{\circ}$ units.

\subsubsection{3-cyanopyridines on gold colloids:}

The comparison between the experiment and calculated value for some of the vibrational modes is presented in Table 3.2. Experimental result suggest that 3-cyanopyridine orients 


\begin{tabular}{|c|c|c|c|c|c|c|c|c|c|c|}
\hline $\begin{array}{l}\text { Band } \\
\text { Assignment }\end{array}$ & $\begin{array}{l}\mathrm{MM} \\
4-\mathrm{CP}\end{array}$ & $\begin{array}{l}\mathrm{MM} \\
\mathrm{Au} / 4 \mathrm{CP}(\text { flat- } \\
\text { on) }\end{array}$ & $\begin{array}{l}\mathrm{MM} \\
\mathrm{Au} / 4 \mathrm{CP}(\mathrm{end}- \\
\text { on) }\end{array}$ & $\begin{array}{l}\text { MM } \\
\text { Au/4CP(coord. } \\
\text { through } \mathrm{CN})\end{array}$ & $\begin{array}{l}\mathrm{Au} / \\
.02 \mathrm{M} \\
4 \mathrm{CP}\end{array}$ & $\begin{array}{l}\mathrm{Au} / .01 \mathrm{M} \\
4 \mathrm{CP}\end{array}$ & $\begin{array}{l}\mathrm{Au} / \\
10^{-3} \mathrm{M} \\
4 \mathrm{CP}\end{array}$ & $\begin{array}{l}\mathrm{Au} / \\
10^{-4} \mathrm{M} \\
4 \mathrm{CP}\end{array}$ & $\begin{array}{l}\mathrm{Au} / \\
10^{-6} \mathrm{M} \\
4 \mathrm{CP}\end{array}$ & $\begin{array}{l}4 \mathrm{CP} \\
\text { (Exp.) }\end{array}$ \\
\hline $\begin{array}{l}\text { Ring } \\
\text { breathing }\end{array}$ & 1007 & 982 & 1033 & 996 & 1004 & 1011 & 1011 & 1011 & 1011 & 1011 \\
\hline$\beta(\mathrm{CH})$ & 1223 & & 1293 & & 1258 & 1208 & 1208 & 1215 & 1215 & 1201 \\
\hline$v(C=C)$ & 1617 & 1612 & 1672 & 1602 & 1602 & 1602 & 1602 & 1611 & 1606 & 1598 \\
\hline$v(C \equiv N)$ & 2206 & 2166 & 2199 & 2219 & 2231 & 2224 & 2224 & 2227 & 2231 & 2235 \\
\hline
\end{tabular}

Table 3.1 Comparison of frequencies of some of the important band assignments obtained from the model system and experiment for $\mathrm{Au} / 4 \mathrm{CP}$ systems(MM=Molecular Mechanics) 
itself on the gold surface through an end-on orientation through the nitrogen atom of the aromatic ring. In the model the distance between the nitrogen of the aromatic ring and the gold surface was set as $0.1 \AA$. This distance gave the best results in comparison with the experiments. The flat-on orientation was developed such that the $\Pi$-system, aromatic nitrogen and nitrile group interacts with the surface. In this case a distance of $2 \AA$ gave the best possible results in close agreement with the experiments. To model a system for endon orientation with coordination through nitrogen, the minimum distance required between the cyanide nitrogen and the gold surface was determined to be $2 \AA$. It was found that this is the minimum distance which has to be set to observe a frequency value for $\mathrm{C} \equiv \mathrm{N}$.

In the table it can be seen that the experimental values agree with the end-on alignment. The ring breathing mode, $\beta(\mathrm{CH})$ and $v(\mathrm{C}=\mathrm{C})$ are shifted upwards when frequencies are calculated with the model system and the frequency value of $v(C \equiv N)$ goes downwards. Hence the model can be considered as a good representation of the real $\mathrm{Au} / 3 \mathrm{CP}$ system. From the model and the calculations, it is reasonable to propose that the orientation of the 3-cyanopyridine molecules on the gold surface is end-on through the nitrogen atom. Via comparisons between the experimental and calculated values, it is possible to infer that the orientation of 3-cyanopyridine on gold is end-on through the nitrogen of the aromatic ring. It was found that the frequencies of the model compared with the frequencies of the experiment when the 3-cyanopyrdine was oriented on the surface such that it is tilted towards the surface at a $90^{\circ}$ angle. It was also found that when the 


\begin{tabular}{|c|c|c|c|c|c|c|c|c|c|}
\hline $\begin{array}{l}\text { Band } \\
\text { Assignment }\end{array}$ & $\begin{array}{l}\mathrm{MM} \\
3 \mathrm{CP}\end{array}$ & $\begin{array}{l}\mathrm{MM} \\
\mathrm{Au} / 3 \mathrm{CP}\end{array}$ & $\begin{array}{l}\mathrm{MM} \\
\mathrm{Au} / 3 \mathrm{CP}\end{array}$ & $\begin{array}{l}\mathrm{Au} / .02 \mathrm{M} \\
3 \mathrm{CP}\end{array}$ & $\begin{array}{l}\mathrm{Au} / .01 \mathrm{M} \\
3 \mathrm{CP}\end{array}$ & $\begin{array}{l}\mathrm{Au} / 10^{-3} \mathrm{M} \\
3 \mathrm{CP}\end{array}$ & $\begin{array}{l}\mathrm{Au} / 10^{-4} \mathrm{M} \\
3 \mathrm{CP}\end{array}$ & $\begin{array}{l}\mathrm{Au} / 10^{-6} \mathrm{M} \\
3 \mathrm{CP}\end{array}$ & $\begin{array}{l}\text { Expt. } \\
3 \mathrm{CP}\end{array}$ \\
\hline & & (end-on) & (flat-on) & & & & & & \\
\hline $\begin{array}{l}\text { Ring } \\
\text { breathing }\end{array}$ & 995 & 1005 & 1002 & 997 & 997 & 1011 & 1023 & 1004 & 976 \\
\hline$\beta(\mathrm{CH})$ & 1180 & 1286 & 1250 & 1228 & 1228 & 1228 & 1228 & 1228 & 1214 \\
\hline$v(C=C)$ & 1611 & 1688 & 1637 & 1580 & 1594 & 1594 & 1596 & 1594 & 1580 \\
\hline$v(\mathrm{C} \equiv \mathrm{N})$ & 2210 & 2207 & 2176 & 2224 & 2221 & 2221 & 2224 & 2224 & 2227 \\
\hline
\end{tabular}

Table 3.2 Comparison of frequencies of some of the important band assignments obtained from model system and experiment for $\mathrm{Au} / 3 \mathrm{CP}$ system(MM=Molecular Mechanics) 
molecule was tilted towards the surface at a $60^{\circ}$ angle, the values obtained for $v(C \equiv N)$ agreed with the value obtained when the orientation is flat on.

From the model and the calculations, it is reasonable to propose that the orientation of the 3-cyanopyridine molecules on the gold surface is end-on through the nitrogen atom and the distance between the 3-cyanopyridine and gold surface is $0.1 \AA$ units.

\subsubsection{2-cyanopyridines on gold colloids:}

The comparison of important band assignments obtained from experiments and calculations is presented in Table 3.3. The shift of ring breathing, $\beta(\mathrm{CH})$ and $v(\mathrm{C}=\mathrm{C})$ is towards higher wavenumbers with respect to the free 2-cyanopyridine molecule only when the model is assumed to be end-on. The shift of $v(\mathrm{C} \equiv \mathrm{N})$ towards a lower wavenumber is observed for end-on orientation. The flat on orientation as expected shifts ring breathing, $\beta(\mathrm{CH})$ and $v(\mathrm{C}=\mathrm{C})$ towards lower wavenumbers with respect to the free molecule. The model with end-on coordination through the nitrile nitrogen shifts $v(\mathrm{C} \equiv N)$ towards higher wavenumber with respect to the free 2-cyanopyridine molecule. These results when compared with the experimental results show that the orientation of 2cyanopyridine on gold surface is end-on with primary interaction with the nitrogen of the aromatic

ring. 


\begin{tabular}{|c|c|c|c|c|c|c|c|c|c|c|}
\hline $\begin{array}{l}\text { Band } \\
\text { Assignment }\end{array}$ & $\begin{array}{l}\mathrm{MM} \\
2 \mathrm{CP}\end{array}$ & $\begin{array}{l}\text { MM } \\
\text { Au/2CP } \\
\text { Flat-on }\end{array}$ & $\begin{array}{l}\mathrm{MM} \\
\mathrm{Au} / 2 \mathrm{CP} \\
\text { End-on }\end{array}$ & $\begin{array}{l}\mathrm{MM} \\
\mathrm{Au} / 2 \mathrm{CP}(\text { coord } \\
\text { Through } \\
\mathrm{C} \equiv \mathrm{N})\end{array}$ & $\begin{array}{l}\mathrm{Au} / .02 \mathrm{M} \\
2 \mathrm{CP}\end{array}$ & $\begin{array}{l}\mathrm{Au} / .01 \mathrm{M} \\
2 \mathrm{CP}\end{array}$ & $\begin{array}{l}\mathrm{Au} / \\
10^{-3} \mathrm{M} \\
2 \mathrm{CP}\end{array}$ & $\begin{array}{l}\mathrm{Au} / \\
10^{-4} \mathrm{M} \\
2 \mathrm{CP}\end{array}$ & $\begin{array}{l}\mathrm{Au} / \\
10^{-6} \mathrm{M} \\
2 \mathrm{CP}\end{array}$ & $\begin{array}{l}2 \mathrm{CP} \\
\text { (Expt.) }\end{array}$ \\
\hline $\begin{array}{l}\text { Ring } \\
\text { breathing }\end{array}$ & \begin{tabular}{|l}
1000 \\
\end{tabular} & 984 & 1040 & 1022 & 1035 & 1035 & 1023 & 1035 & 1023 & 1000 \\
\hline$\beta(\mathrm{CH})$ & \begin{tabular}{|l|}
1178 \\
\end{tabular} & 1160 & 1293 & 1220 & - & 1290 & - & 1279 & - & 1279 \\
\hline$v(\mathrm{C}=\mathrm{C})$ & 1593 & 1573 & 1664 & 1597 & 1593 & 1593 & 1593 & 1593 & 1616 & 1565 \\
\hline$v(\mathrm{C} \equiv \mathrm{N})$ & 2189 & 2165 & 2170 & 2257 & 2205 & 2205 & 2199 & 2199 & 2199 & 2216 \\
\hline
\end{tabular}

Table 3.3 Comparison of frequencies of some of the important band assignments obtained from model system and experiment for $\mathrm{Au} / 2 \mathrm{CP} \operatorname{system}(\mathrm{MM}=$ Molecular Mechanics $)$ 


\subsubsection{4-biphenylcarbonitriles on gold colloids:}

The comparisons of important vibrational modes between experimental values and calculation values is shown in Table 3.4. The table compares the frequencies of end-on and flat-on orientations with the experimental values. It is seen from the models that when the orientation is end-on such that the nitrile group is away from the surface, there is no shift for the nitrile frequency. A shift in the nitrile frequency is observed only when the orientation is flat on and when the orientation is end-on through nitrile group nitrogen. The flat on orientation shifts $v(C \equiv N)$ towards a lower wavenumber whereas end-on through nitrile nitrogen shifts $v(C \equiv N)$ towards a higher wavenumber. The model with end-on orientation through the phenyl ring does not shift the value for $v(C \equiv N)$. From experiments it is found that there is a shift for $v(\mathrm{C} \equiv \mathrm{N})$ towards lower wavenumbers. This suggests that the orientation of the molecule 4-biphenylcarbonitrile on the gold surface is flat-on.

\subsubsection{Aminomethylpyridine on copper colloids:}

The comparison of some of the important vibrational modes between the experimental and calculated frequencies are presented in Tables 3.5, 3.6 and 3.7 for 4-, 3- and 2aminomethylpyridines respectively. It is assumed that the end-on orientation shifts ring breathing, $\beta(\mathrm{CH})$ and $\beta\left(\mathrm{NH}_{2}\right)$ and $\mathrm{v}(\mathrm{C}=\mathrm{C})$ towards lower wavenumbers as compared to the free molecule and flat-on orientation shifts the above mentioned vibrational modes towards higher wavenumbers. It can be seen that when the model is flat-on, the frequencies for the above mentioned vibrational modes are shifted towards higher 


\begin{tabular}{|c|c|c|c|c|c|c|c|c|}
\hline $\begin{array}{l}\text { Band } \\
\text { Assignment }\end{array}$ & $\begin{array}{l}\mathrm{MM} \\
4 \mathrm{BPN}\end{array}$ & $\begin{array}{l}\mathrm{MM} \\
\mathrm{Au} / 4 \mathrm{BPN} \\
\text { (flat-on) }\end{array}$ & $\begin{array}{l}\mathrm{MM} \\
\mathrm{Au} / 4 \mathrm{BPN} \\
\text { (end-on) }\end{array}$ & $\begin{array}{l}\text { MM } \\
\text { Au/4BPN } \\
\text { Coordination } \\
\text { Through CN }\end{array}$ & $\begin{array}{l}\mathrm{Au} / 10^{-4} \mathrm{M} \\
4 \mathrm{BPN}\end{array}$ & $\begin{array}{l}\mathrm{Au} / 10^{-5} \mathrm{M} \\
4 \mathrm{BPN}\end{array}$ & $\begin{array}{l}\mathrm{Au} / 10^{-6} \mathrm{M} \\
4 \mathrm{BPN}\end{array}$ & $\begin{array}{l}4 \mathrm{BPN} \text { in } \\
\mathrm{CCl}_{4}\end{array}$ \\
\hline $\begin{array}{l}\text { Ring } \\
\text { breathing }\end{array}$ & 1017 & 971 & 1018 & 1026 & 973 & 980 & 994 & 994 \\
\hline$\beta(\mathrm{CH})$ & 1237 & 1233 & 1201 & 1251 & 1207 & 1214 & 1200 & 1216 \\
\hline$v(C=C)$ & 1642 & 1646 & 1685 & 1638 & 1578 & 1578 & 1578 & 1606 \\
\hline$v(\mathrm{C} \equiv \mathrm{N})$ & 2203 & 2183 & 2202 & 2270 & 2208 & 2208 & 2166 & 2220 \\
\hline
\end{tabular}

Table 3.4 Comparison of frequencies of some of the important band assignments obtained from model system and experiment for $\mathrm{Au} / 4 \mathrm{BPN}$ system $(\mathrm{MM}=$ Molecular Mechanics $)$ 
wavenumbers and when the model is end-on, the frequencies are shifted towards lower wavenumbers. The calculated frequencies agrees with the experimental trend.

The models were developed such that in the end-on orientation, the distance between the aromatic nitrogen and the copper surface was set at $0.1 \AA$ and in the flat-on orientation, the distance between the ring and the surface was set as $2 \AA$. This model gave the best results when compared to the experimental trend. 


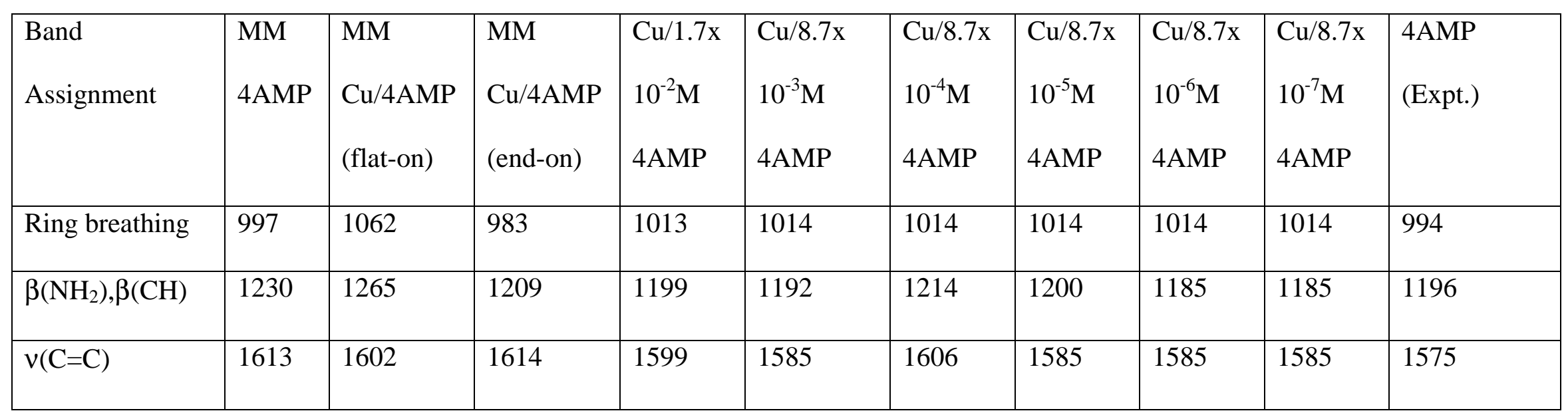

Table 3.5 Comparison of values of frequencies of some of the important band assignments obtained from model system and experiment for $\mathrm{Cu} / 4 \mathrm{AMP}$ system $(\mathrm{MM}=$ Molecular Mechanics) 


\begin{tabular}{|c|c|c|c|c|c|c|c|c|c|c|}
\hline $\begin{array}{l}\text { Band } \\
\text { Assignment }\end{array}$ & $\begin{array}{l}\text { MM } \\
\text { 3AMP }\end{array}$ & $\begin{array}{l}\text { MM } \\
\mathrm{Cu} / 3 \mathrm{AMP} \\
\text { Flat-on }\end{array}$ & $\begin{array}{l}\mathrm{MM} \\
\mathrm{Cu} / 3 \mathrm{AMP} \\
\text { End-on }\end{array}$ & $\begin{array}{l}\mathrm{Cu} / 1.7 \mathrm{x} \\
10^{-2} \mathrm{M} \\
3 \mathrm{AMP}\end{array}$ & $\begin{array}{l}\mathrm{Cu} / 8.7 \mathrm{x} \\
10^{-3} \mathrm{M} \\
3 \mathrm{AMP}\end{array}$ & $\begin{array}{l}\mathrm{Cu} / 8.7 \mathrm{x} \\
10^{-4} \mathrm{M} \\
3 \mathrm{AMP}\end{array}$ & $\begin{array}{l}\mathrm{Cu} / 8.7 \mathrm{x} \\
10^{-5} \mathrm{M} \\
3 \mathrm{AMP}\end{array}$ & $\begin{array}{l}\mathrm{Cu} / 8.7 \mathrm{x} \\
10^{-6} \mathrm{M} \\
3 \mathrm{AMP}\end{array}$ & $\begin{array}{l}\mathrm{Cu} / 8.7 \mathrm{x} \\
10^{-7} \mathrm{M} \\
3 \mathrm{AMP}\end{array}$ & $\begin{array}{l}\text { 3AMP } \\
\text { (Expt.) }\end{array}$ \\
\hline Ring breathing & 1010 & 1078 & 975 & 1031 & 1020 & 1028 & 1028 & 1028 & 1006 & 1014 \\
\hline$\beta(\mathrm{CH})$ & & & & & & & & & & \\
\hline$v(C=C)$ & 1571 & 1603 & 1546 & 1585 & 1585 & 1585 & 1585 & 1585 & 1585 & 1571 \\
\hline
\end{tabular}

Table 3.6 Comparison of frequencies of some of the important band assignments obtained from model system and experiment for $\mathrm{Cu} / 3 \mathrm{AMP}$ system $(\mathrm{MM}=$ Molecular Mechanics) 


\begin{tabular}{|c|c|c|c|c|c|c|c|c|c|c|}
\hline $\begin{array}{l}\text { Band } \\
\text { Assignment }\end{array}$ & $\begin{array}{l}\mathrm{MM} \\
2 \mathrm{AMP}\end{array}$ & $\begin{array}{l}\mathrm{MM} \\
\mathrm{Cu} / 2 \mathrm{AMP} \\
\text { Flat-on }\end{array}$ & $\begin{array}{l}\mathrm{MM} \\
\mathrm{Cu} / 2 \mathrm{AMP} \\
\text { End-on }\end{array}$ & $\begin{array}{l}\mathrm{Cu} / 1.7 \mathrm{x} \\
10^{-2} \mathrm{M} \\
2 \mathrm{AMP}\end{array}$ & $\begin{array}{l}\mathrm{Cu} / 8.7 \mathrm{x} \\
10^{-3} \mathrm{M} \\
2 \mathrm{AMP}\end{array}$ & $\begin{array}{l}\mathrm{Cu} / 8.7 \mathrm{x} \\
10^{-4} \mathrm{M} \\
2 \mathrm{AMP}\end{array}$ & $\begin{array}{l}\mathrm{Cu} / 8.7 \mathrm{x} \\
10^{-5} \mathrm{M} \\
2 \mathrm{AMP}\end{array}$ & $\begin{array}{l}\mathrm{Cu} / 8.7 \mathrm{x} \\
10^{-6} \mathrm{M} \\
2 \mathrm{AMP}\end{array}$ & $\begin{array}{l}\mathrm{Cu} / 8.7 \mathrm{x} \\
10^{-7} \mathrm{M} \\
2 \mathrm{AMP}\end{array}$ & $\begin{array}{l}\text { 2AMP } \\
\text { (Expt.) }\end{array}$ \\
\hline Ring breathing & 991 & 1016 & 1016 & 1021 & 1006 & 1006 & 1006 & 1006 & 1028 & 1014 \\
\hline$\beta\left(\mathrm{NH}_{2}\right), \beta(\mathrm{CH})$ & 1228 & 1191 & 1243 & 1242 & 1228 & 1200 & 1200 & 1213 & 1214 & 1228 \\
\hline$v(C=C)$ & 1593 & 1567 & 1521 & 1585 & 1585 & 1585 & 1587 & 1585 & 1585 & 1585 \\
\hline
\end{tabular}

Table 3.7 Comparison of frequencies of some of the important band assignments obtained from model system and experiment for $\mathrm{Cu} / 2 \mathrm{AMP}$ system $(\mathrm{MM}=$ Molecular Mechanics $)$ 


\section{Summary}

The orientation of adsorbates on metal colloids was studied by modeling the reactions using Spartan Pro 1.0. The distance, angle and the dihedral angle between the metal surface and the adsorbate were varied until a model was reached which gave frequency values that agreed with the experimental trend. The calculations were performed with the Molecular Mechanics Force Field Method to obtain the frequencies of the vibrational modes. The frequencies obtained for the developed models were in close agreement with the experimental trend and hence the molecule-surface geometry can be considered as a good model for the metal-adsorbate system. 


\section{References}

1. PC Spartan Pro V1.0, Copyright 1996-1999 Wavefunction Inc.

2. D. H. Andrews, Physical Review Letters, 36, 544, 1930.

3. F. H. Westheimer, J. E. Meyer, Journal of Chemical Physics, 14, 733, 1946.

4. A. Hinchliffe in Modelling Molecular Structures edited by Wiley Tutorial Series in Theoretical Chemistry, p.17, 1996. 


\section{CHAPTER 4}

\section{Scope For Future Investigation}

In our study, we attempted to investigate the orientation of the adsorbates on metal colloids. It was found that the nature of the metal is important in deciding the orientation.

It was found that gold does not change the orientation of the adsorbate whereas copper changes the orientation of the adsorbate. Further studies can be performed to determine the specific reasons why copper and gold colloids behave differently.

Attempts can be made to study the force of interaction between the adsorbate and the metal. Attempts can also be made to separate the adsorbate and the metal system.

There is a vast scope for theoretical investigations that can be done for these systems. There is still not a good enough model that can adequately describe the nature of the surface enhanced Raman effect. 


\section{VITA}

Ramaa Ramakrishnan was born as the third daughter among four daughters to a bank official N.V.Ramakrishnan and Shantha Ramakrishnan on September $11^{\text {th }}, 1974$ at Madras, India. She attended her school at Madras, India. She received her bachelors degree in chemistry from Meenakshi College for women, Madras, India , a college affliated to the University of Madras in May 1995. She then joined Indian Institute of Technology, Madras, India for the masters program. She received her masters degree in chemistry in May 1997. She then officially joined the graduate program in West Virginia University in Fall '98. She worked under Dr. Paul W.Jaodzinski for the mastes thesis. She specialized her thesis in colloidal and surface chemistry. She is currently a candidate for the masters degree in physical chemistry at West Virginia University. 